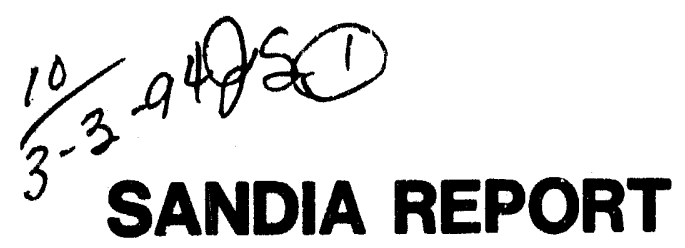

SAND92-1842 - UC-722

Unlimited Release

Printed December 1993

\title{
Use of Inelastic Design for Radioactive Material Transportation Packages
}

\author{
M. W. Heinstein, D. J. Ammerman
}

\section{Propered by}

Bendla Mationel Leboratories

Albuquerawe, Now Moxlco 87186 and Luvormore, Calliomla 94880

for the United states Department of Enorey

under Contrect DE-ACO4-04ALEs000 
Inoued by Sandia National Laboratories, operated for the United States Department of Energy by Sandia Corporation.

NOTICE: This report was prepared as an account of work sponsored by an agency of the United States Government. Neither the United States Government nor any agency thereof, nor any of their employees, nor any of their contractors, subcontractors, or their employees, makes any warranty, express or implied, or assumes ary legal liability or responsibility for the accuracy, completoners, or usefulnese of any information, apparatus, product, or procens diecloned, or represents that its use would not infringe privately owned rights. Roference herein to any specific commercial product, process, or corvice by trade name, trademark, manufacturer, or otherwise, does not necesarily constitute or imply its endorsemert, recommendation, or favoring by the United States Government, any agency thereof or any of their contractors or subcontractors. The views and opinions expressed herein do not neceasarily state or refloct those of the United States Government, any agency thereof or any of their contractors.

Printed in the United States of America. This report has been reproduced directly from the best available copy.

Available to DOE and DOE contractors from Office of Scientific and Technical Information PO Box 62

Oak Ridige, TN 37831

Prices available from (615) 576-8401, FTS 626-8401

Available to the public from

National Technical Information Service

US Department of Commerce

5285 Port Royal Rd

Springfield, VA 22161

NTIS price codes

Printod copy: A03

Microfiche copy: A01 
SAND92-1842

Distribution

TTC-1275

Category UC-722

Unlimited Release

Printed December 1993

\title{
Use of Inelastic Design for Radioactive Material Transportation Packages*
}

\author{
M. W. Heinstein \\ Engineering Mechanics and Material Modeling Department \\ D. J. Ammerman \\ Transportation Systems Technology Department \\ Sandia National Laboratories ${ }^{* *}$ \\ Albuquerque, NM 87185
}

\begin{abstract}
There is much interest within the radioactive material transportation container design community in the use of inelastic analysis. In other industries where inelastic analysis is used in design there is typically an improved knowledge of the capacity of the structure and a more efficient use of material. This report describes the results of a program in which the incentives for inelastic analysis for radioactive material transport container design were investigated to determine if there are similar benefits. Detailed are the elastic and inelastic analyses of two containers subjected to impacts onto a rigid target following a thirty-foot free fall in end-on, side-on, and center-of-gravityover-corner orientations.
\end{abstract}

* This work performed at Sandia National Laboratories, Albuquerque, New Mexico, supported by the United States Department of Energy under Contract DE-AC04-94AL85000

${ }^{* *}$ A United States Department of Energy Facility

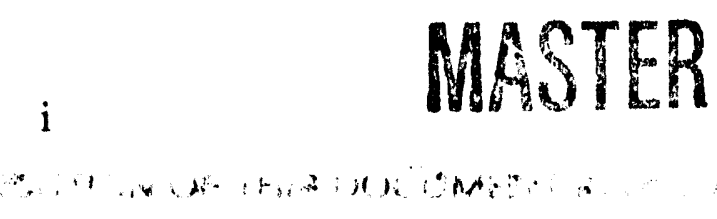




\section{Acknowledgements}

The authors would like to thank all of the people who have helped in this program. G. Wellman from the Engineering Mechanics and Material Modeling Department provided helpful guidance throughout the program. J. Ludwigsen from the Transportation Systems Technology Department helped by reviewing the report. Finally the authors would like to thank the Department of Energy Office of Environmental Restoration and Waste Management Transportation Management Division for providing the funding for this program. 


\section{Table of Contents}

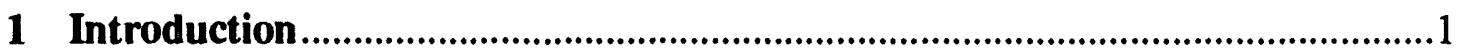

2 Baseline Package ............................................................................................

3 Material Models and Design Limits ...................................................................7

4 End Impact

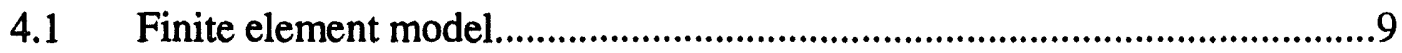

4.2 Elastic design of rail cask ............................................................................10

4.3 Inelastic design of rail cask .......................................................................11

4.4 Comparison of elastic and inelastic design of rail cask ................................14

$4.5 \quad$ Elastic design of truck cask........................................................................16

4.6 Inelastic design of truck cask ..................................................................17

4.7 Comparison of elastic and inelastic design of truck cask .............................18

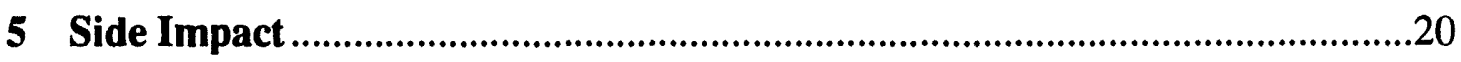

5.1 Finite element model...............................................................................20

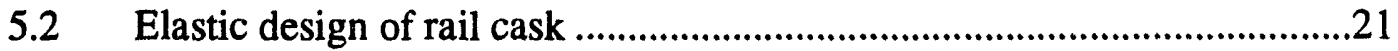

$5.3 \quad$ Inelastic design of rail cask ...........................................................................22

5.4 Comparison of elastic and inelastic design of rail cask ...............................24

$5.5 \quad$ Elastic design of truck cask............................................................................25

5.6 Inelastic design of truck cask .................................................................26

5.7 Comparison of elastic and inelastic design of truck cask ...........................27

6 CG-Over Corner Impact....................................................................................29

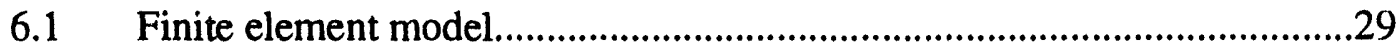

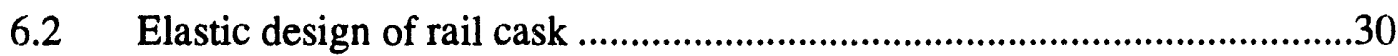

$6.3 \quad$ Inelastic design of rail cask .............................................................................32

6.4 Comparison of elastic and inelastic design of rail cask .................................33

$6.5 \quad$ Elastic design of truck cask.........................................................................34

6.6 Inelastic sesign of truck cask .....................................................................35

6.7 Comparison of elastic and inelastic design of truck cask ..............................37

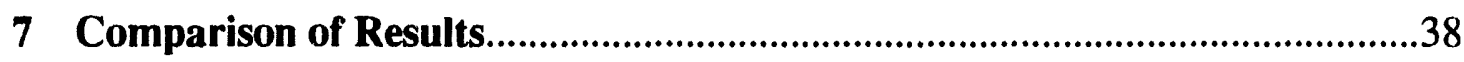

8 Issues Involved in Conducting Accurate Analyses ...........................................39

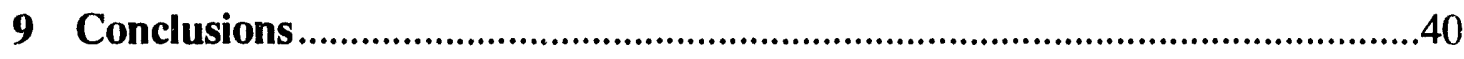

10 References ...................................................................................................4 


\section{List of Figures}

Figure 1. Rail and truck RAM transportation package construction3

Figure 2. Rail and Truck Cask Side wall5

Figure 3. Engineering stress vs. true strain for 304 Stainless steel8

Figure 4. Finite element models for the rail and truck RAM transportation package for $30 \mathrm{ft}$. end impact scenario 9

Figure 5. Deformed elastic rail cask after $30 \mathrm{ft}$. end drop 10

Figure 6. Maximum von Mises stress during the $30 \mathrm{ft}$. end drop of elastic rail cask11

Figure 7. Maximum von Mises stress in the redesigned elastic rail cask during $30 \mathrm{ft}$. end drop (contents nearly full) 11

Figure 8. Deformed inelastic rail cask after $30 \mathrm{ft}$. end drop 12

Figure 9. Maximum von Mises stress during the $30 \mathrm{ft}$. end drop of inelastic rail cask12

Figure 10. Maximum equivalent plastic strain in the inelastic rail cask13

Figure 11. Maximum von Mises after rebound of inelastic rail cask subjected to $30 \mathrm{ft}$. end impact (contents nearly full) 13

Figure 12. Kinetic energy and G-loading history for elastic and inelastic rail cask subjected to $30 \mathrm{ft}$ end drop 14

Figure 13. Inner and outer shell locations in the nearly full cask where maximum von Mises stress occurs 14

Figure 14. Von Mises stress history for two elements at location A on the inner shell of the nearly full cask 15

Figure 15. Von Mises stress history for several elements at location B on the outer shell of the nearly full cask 15

Figure 16. Deformed elastic truck cask after $30 \mathrm{ft}$. end drop16

Figure 17. Maximum von Mises stress during the $30 \mathrm{ft}$. end drop of elastic truck cask with contents full and nearly full16

Figure 18. Deformed inelastic truck cask after $30 \mathrm{ft}$. end drop 17

Figure 19. Maximum von Mises stress in the cask shells during $30 \mathrm{ft}$ end impact of inelastic truck cask with contents full and nearly full 17

Figure 20. Equivalent plastic strain in the inner shell of inelastic truck cask 18

Figure 21. Kinetic energy history for elastic and inelastic truck cask subjected to $30 \mathrm{ft}$ end drop 18

Figure 22. G-loading history for elastic and inelastic truck cask subjected to 30 ft. end drop 18

Figure 23. Finite element models for the rail and truck RAM transportation package $30 \mathrm{ft}$. end drop scenario 20

Figure 24. Deformed elastic rail cask after $30 \mathrm{ft}$. side drop21

Figure 25. Maximum von Mises stress during the $30 \mathrm{ft}$. side drop of elastic rail cask22

Figure 26. Deformed inelastic rail cask after $30 \mathrm{ft}$.side drop22

Figure 27. Maximum von Mises stress during the $30 \mathrm{ft}$. side drop of inelastic rail cask23

Figure 28. Equivalent plastic strain after 30-foot side impact of rail cask23 
Figure 29. Kinetic energy history for elastic and inelastic rail cask subjected to $30 \mathrm{ft}$ side drop 24

Figure 30. G-loading history for elastic and inelastic rail cask subjected to 30 ft. side drop24

Figure 31. Deformed elastic truck cask after $30 \mathrm{ft}$. side drop25

Figure 32. Maximum von Mises stress during the $30 \mathrm{ft}$. side drop of elastic truck cask 25

Figure 33. Deformed inelastic truck cask after $30 \mathrm{ft}$.side drop26

Figure 34. Von Mises stress in outer shell at $22.5 \mathrm{~ms} .26$

Figure 35. Maximum von Mises stress during the $30 \mathrm{ft}$. side drop of inelastic truck cask 27

Figure 36. Equivalent plastic strain after 30-foot side drop of truck cask27

Figure 37. Kinetic energy history for elastic and inelastic truck cask subjected to $30 \mathrm{ft}$ side drop 28

Figure 38. G-loading history for elastic and inelastic truck cask subjected to $30 \mathrm{ft}$. side drop 28

Figure 39. Finite element models for the rail and truck RAM transportation package $30 \mathrm{ft}$. corner drop scenario 29

Figure 40. Deformed elastic rail cask after $30 \mathrm{ft}$. corner drop30

Figure 41. Von Mises stress history in the outer shell (for 0.6 in. thickness) of the elastic rail cask. Displacements are magnified by $5 x .31$

Figure 42. Maximum von Mises stress during the $30 \mathrm{ft}$. corner drop of elastic rail cask (for 3.5 in. outer shell thickness) 31

Figure 43. Deformed inelastic rail cask after $30 \mathrm{ft}$.corner drop32

Figure 44. Maximum von Mises stress during the $30 \mathrm{ft}$. corner drop of inelastic rail cask 32

Figure 45. Equivalent plastic strain after 30-foot corner drop of rail cask33

Figure 46. Kinetic energy history for elastic and inelastic rail cask subjected to $30 \mathrm{ft}$ corner drop34

Figure 47. G-loading history for elastic and inelastic rail cask subjected to 30 ft. corner drop34

Figure 48. Deformed elastic truck cask after $30 \mathrm{ft}$. corner drop34

Figure 49. Maximum von Mises stress during the $30 \mathrm{ft}$. corner drop of elastic truck cask 35

Figure 50. Deformed inelastic truck cask after $30 \mathrm{ft}$. corner drop35

Figure 51. Maximum von Mises stress during the $30 \mathrm{ft}$. corner drop of inelastic truck cask 36

Figure 52. Equivalent plastic strain after 30-foot corner drop of truck cask36

Figure 53. Kinetic energy history for elastic and inelastic truck cask subjected to $30 \mathrm{ft}$ corner drop37

Figure 54. G-loading history for elastic and inelastic truck cask subjected to 30 ft. corner drop37 


\section{Lisi of Tables}

Table 1: Baseline Rail Cask Dimensions (inches) 4

Table 2: $\quad$ Baseline Truck Cask Dimensions (inches) …................................................4

Table 3: $\quad$ Material Properties............................................................................. 


\section{Introduction}

In the design of radioactive material transportation containers it is necessary to assess their ability to withstand the hypothetical accident environments of 10CFR71. Two of these accident environments involve structural assaults to the package, the 9-meter free fall onto an essentially unyielding target and the 1 meter drop onto a puncture spike. The determination of the packages ability to withstand these events can be accomplished in four ways: by testing, by analysis, by a combination of testing and analysis, and by comparison with similar packages that have been demonstrated to withstand the events. If the package designer chooses to demonstrate package performance by means of analysis the package is said to be designed by analysis. It is this type of design that this report will discuss.

Traditional design by analysis techniques have followed the requirements of NRC Regulatory Guide 7.6 [1] to determine the adequacy of the design. This guide requires elastic analysis of the structural portions of the package and sets limits for maximum stresses in the containment boundary. The guide does not require elastic treatment of the non-structural portions of the package, such as impact limiters and shielding. Also there are no provisions in the guide for designs where structural instability may occur, so if the designer wishes to follow the guide it must be demonstrated that there will be none of these instabilities.

In general practice, the design of a container is completed in steps. An usual first step is the design of the impact limiter. From this step the designer will determine the accelerations of the package in the impact test based on an assumed behavior of the impact limiter. The maximum acceleration is then used as a load to be applied to the package in a quasistatic analysis. This step makes the package design a static analysis problem, rather than a more difficult dynamic one. The major difficulty with this step is the assumption of the distribution of contact stresses between the package and impact limiter that must be made. For end-drop orientations a typical assumption is uniform stress over the end of the package. For side-drop orientations a sinusoidal distribution is very typical. For orientations between these two extremes more creativity is required in choosing a contact stress distribution, but this can be readily accomplished. Once the distribution of contact stresses is determined the analysis proceeds using quasistatic elastic analysis techniques. These techniques range from simple hand calculations to more complicated finite element calculations. Generally all sources of nonlinearity are ignored and fabrication stresses, bolt preload stresses, and thermal stresses are simply added to the stresses from the impact analysis.

This type of quasistatic elastic analysis requires the designer to assume an acceleration response of the impact limiter, linear elastic material behavior during the impact event, and finally a superposition of stresses from various sources. With these assumptions, it is difficult to determine the true response of the package to the impact event. This leads to a question of what effect various assumptions have on the package design and ultimately what is the effect on the overall safety assessment when subjected to the impact event.

For these reasons it is desirable to have a more accurate design methodology that involves inelastic transient dynamic analysis. In this design methodology, all of the components that contribute to nonlinear behavior are included in the analysis. This allows an accurate modelling of the contact forces between the package, impact limiter, and unyielding target, thereby eliminating one of the major assumptions of the traditional quasistatic analysis techniques. 
Furthermore, fabrication stresses, bolt preload stresses, and other sources of stress are considered in a physically correct manner that allows non-linear interaction with the impact stress during the impact event. The goal of this work is to determine if an improved knowledge of the behavior of the package results from using transient dynamic inelastic analysis. In order to determine this improved behavior the transient dynamic elastic analysis technique is compared to transient dynamic elastic analysis. A transient dynamic elastic analysis is chosen rather than the more traditional quasistatic elastic analysis so that the effect of assuming elastic material behavior of the structural steel container can be determined without the other complicating assumptions required by the quasistatic analysis. For this purpose the only difference in the set of analyses presented here is that in one case (the inelastic analyses) the container constructed of stainless steel shells and cask ends were modelled as an inelastic material and in the other case (the elastic analyses) the stainless steel shells and ends of the cask were modelled as an elastic material. All other materials are modelled as accurately as possible to provide the appropriate response to the impact. This ensures that the structural elements of the cask, the stainless steel shells and ends, are subjected to the most accurate loading conditions during the impact.

In this report the benefits of using transient dynamic inelastic analysis in the design of radioactive material (RAM) transportation packages will be explored via two sample designs for shipping a bulk quantity high level RAM waste. The waste is assumed to have very little strength but high volumetric stiffness and a specific weight of 1.7 . It is assumed that the shielding requirements for the package are similar to those for spent fuel. The two packages are a rail cask that utilizes lead for its gamma shielding and a truck cask that utilizes depleted uranium for its gamma shielding. Both packages use 304 stainless steel shells on the inside and outside of the gamma shielding and solid stainless steel ends.

In order to contrast the transient dynamic elastic analysis and inelastic analysis, a design criteria must be established for each. For the elastic analysis, the design criteria are those prescribed by Regulatory Guide 7.6 [1]. There are several difficulties in establishing transient dynamic inelastic design criterion. The most problematic of these is what value to use as an acceptance criterion. Some of the possible acceptance criteria are based on: maximum von Mises stress, maximum Tresca stress, maximum principal strain, maximum permanent deformation, maximum allowable load proportional to failure load, limit on through-wall plasticity, and a maximum strain energy as a proportion of the strain energy at material failure (or strain energy at peak strength). Once an acceptance criterion has been established, another problem is to determine if the package meets it. There are two sides to this problem - how to determine the value in the package (for example maximum strain, an analysis problem), and how to determine the allowable value (a material problem). For this work the acceptance criterion is stress based. While it may not be the best criterion for an energy limited event such as a cask impact, it has the benefit of being recognized by a national code writing organization [3].

This approach will demonstrate how an inelastic analysis based acceptance criterion affects the design of a cask when compared to an elastic analysis based acceptance criterion. Differences in loading paths, locations of maximum stress, magnitudes of maximum stress, and required shell thickness will be shown. 


\section{Baseline Package}

Generic rail and truck RAM transportation packages are considered in this study. Both are constructed with gamma shielding, inner and outer 304 stainless steel shells, and solid stainless steel end walls as shown in Figure 1. In addition, both packages are encased in neutron shielding, a 304 stainless steel neutron shielding shell, and polyurethane foam impact limiters.
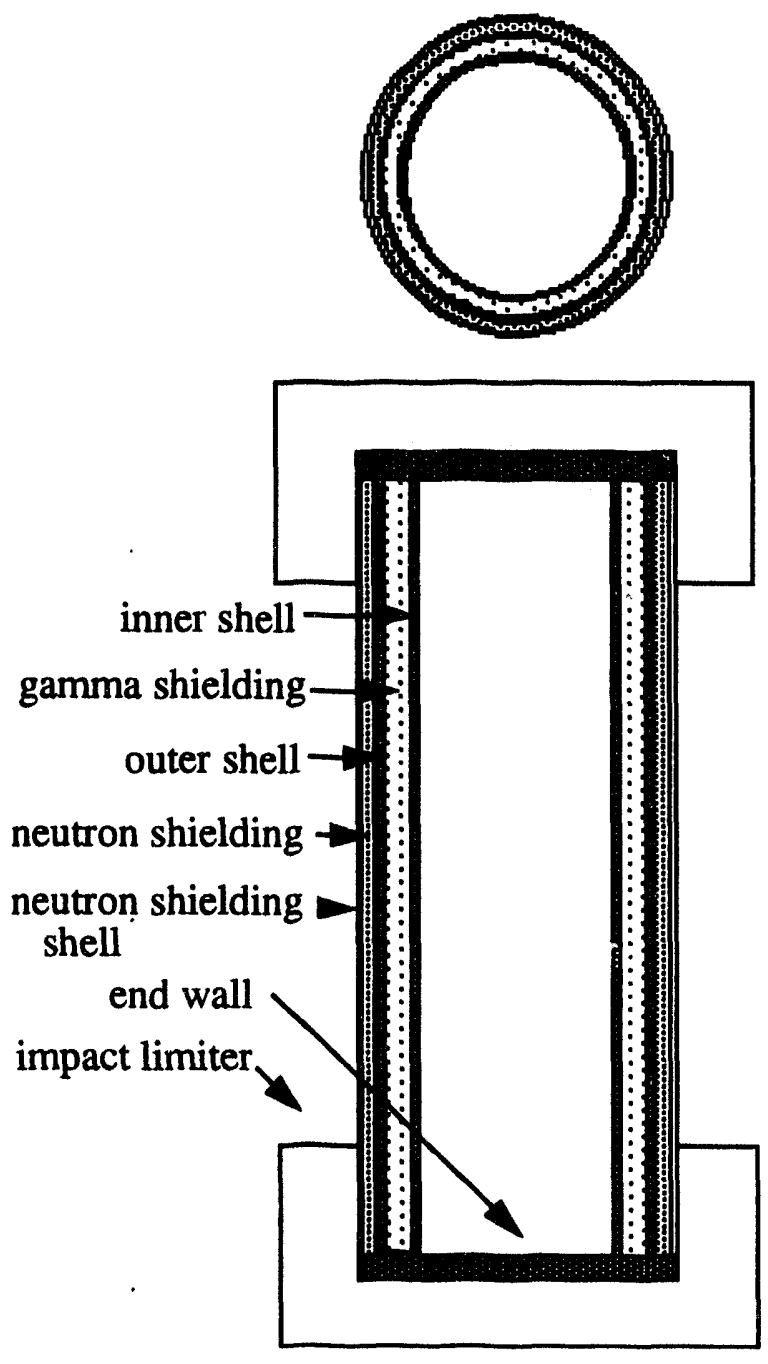

Rail Cask
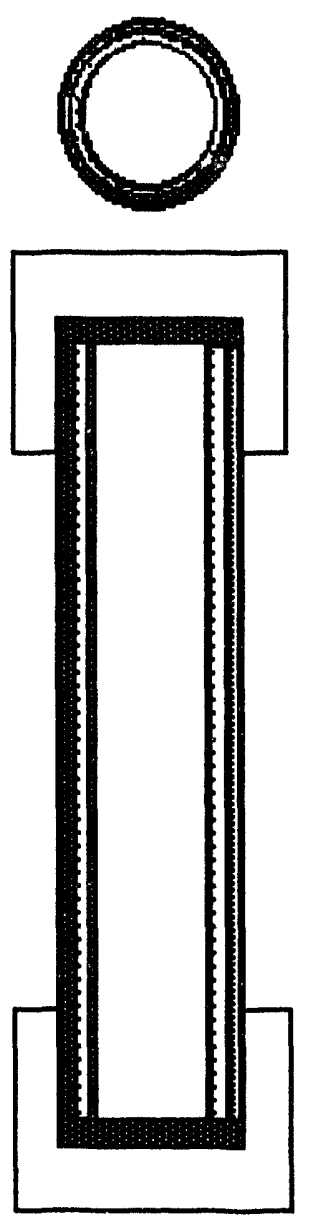

Truck Cask

Figure 1. Rail and truck RAM transportation package construction

The dimensions for the baseline rail and truck casks are given in Table 1 and Table 2 respectively. The rail cask is much larger in diameter than the truck cask. Besides the difference in size, the two packages use different materials for the gamma shielding. The rail cask utilizes lead, and the truck cask uses depleted uranium. 
Table 1: Baseline Rail Cask Dimensions (inches)

\begin{tabular}{|l|l|l|l|l|}
\hline & \multicolumn{1}{|c|}{ ID } & Thickness & \multicolumn{1}{c|}{ Length } & Material \\
\hline \hline Inner shell & 59.90 & 0.30 & 171.6 & SS 304L \\
\hline Gamma Shield & 60.50 & 5.98 & 171.6 & Lead \\
\hline Outer shell & 72.46 & 0.60 & 171.6 & SS 304L \\
\hline neutron shield & 73.66 & 5.00 & 171.6 & \\
\hline neutron shield shell & 83.66 & 0.125 & 171.6 & SS 304L \\
\hline ends & & 6.88 & & SS 304L \\
\hline impact limiter (side) & & 20.0 & 24.0 & $\begin{array}{l}\text { polyurethane } \\
\text { foam (20 lb.) }\end{array}$ \\
\hline impact limiter (end) & & 15.0 & & $\begin{array}{l}\text { polyurethane } \\
\text { foam (20 lb.) }\end{array}$ \\
\hline
\end{tabular}

Table 2: Baseline Truck Cask Dimensions (inches)

\begin{tabular}{|l|l|l|l|l|}
\hline & \multicolumn{1}{|c|}{ ID } & Thickness & \multicolumn{1}{c|}{ Length } & \multicolumn{1}{c|}{ Material } \\
\hline \hline Inner shell & 24.1 & 0.20 & 171.6 & SS 304L \\
\hline Gamma Shield & 24.5 & 2.95 & 171.6 & $\begin{array}{l}\text { Depleted Ura- } \\
\text { nium }\end{array}$ \\
\hline Outer shell & 30.4 & 0.50 & 171.6 & SS 304L \\
\hline neutron shield & 31.4 & 3.00 & 171.6 & \\
\hline neutron shield shell & 37.4 & 0.125 & 171.6 & SS 304L \\
\hline ends & & 6.88 & & SS 304L \\
\hline impact limiter (side) & & 15.0 & 24.0 & $\begin{array}{l}\text { polyurethane } \\
\text { foam (20 lb.) }\end{array}$ \\
\hline impact limiter (end) & & 15.0 & & $\begin{array}{l}\text { polyurethane } \\
\text { foam (20 lb.) }\end{array}$ \\
\hline
\end{tabular}


In all inelastic and elastic analyses, structural strength was ignored for the neutron shielding and the neutron shielding shell. The mass of this shielding was added to the $3 \mathrm{C} 7$ stainless steel outer shell by adjusting its density:

$$
\rho g_{\text {outer-shell }}=\frac{\left((\rho g)_{s s} \int_{r^{3}}^{r 4} r d r+(\rho g)_{n s} \int_{r 4}^{r 5} r d r+(\rho g)_{n s s} \int_{r 5}^{r 6} r d r\right)}{\left(\int_{r 3}^{r 4 d r} r d\right.}
$$

where, r3, r4, r5 and r6 refer to wall dimensions shown in Figure 2, ss refers to the stainless steel outer shell, $n s$ the neutron shielding, and $n s s$ the neutron shielding shell. The resulting density for the outer stainless steel shell was $0.67885 \mathrm{lb} / \mathrm{in}^{3}$ for the rail cask and $0.615 \mathrm{lb} / \mathrm{in}^{3}$ for the truck cask.

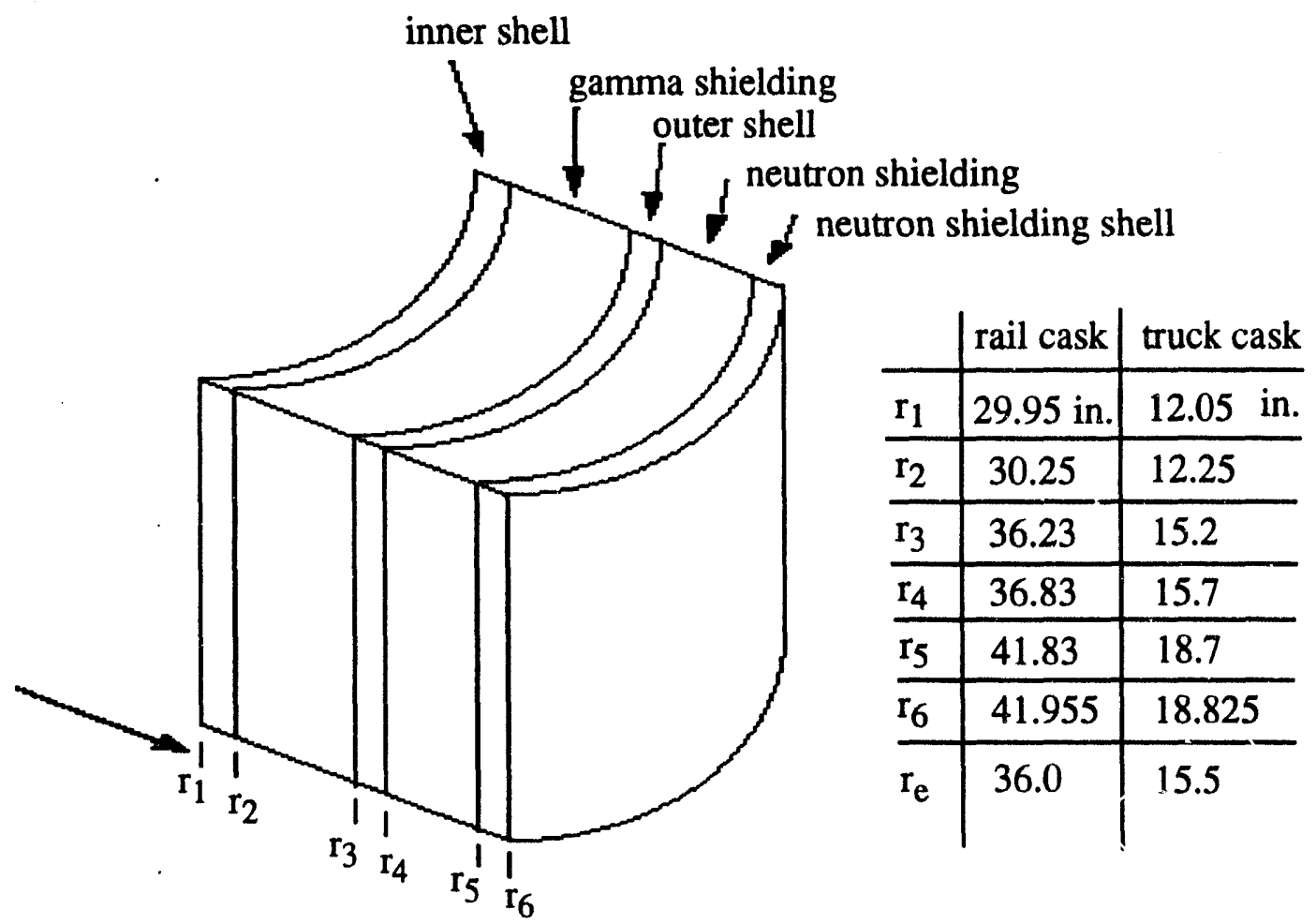

Figure 2. Rail and Truck Cask Side wall

In addition, the density of the cask lids or end walls was adjusted to match the mass/unit area of the side walls. The side walls consist of the inner and outer stainless steel shells, the gamma shielding, and the neutron shielding incluäing its shell. The resulting expression for the density of the end walls is: 


$$
\begin{aligned}
& P g_{\text {end-wall }}=\left((\rho g)_{\text {is }} \int_{0}^{1 / r_{\text {er }} 2} \int_{\mathrm{r} 1}^{1 / r_{\text {er }} 3} r d r d \theta+(\rho g)_{g s} \int_{0}^{1} \int_{\mathrm{r} 2} r d r d \theta+\right. \\
& (\rho g)_{08} \int_{0}^{1 / r_{\text {er }} 4} \int_{\mathrm{r} 3}^{1 / \mathrm{r}_{\mathrm{or}} 5} \mathrm{rdrd} \theta+(\rho g)_{\mathrm{ns}} \int_{0} \int_{\mathrm{r} 4} \mathrm{rdrd} \theta+ \\
& \left.(\rho g)_{\mathrm{nss}} \int_{0}^{1 / \mathrm{r}_{\mathrm{er}} 6} \int_{\mathrm{r} 5}^{\mathrm{rddr} \theta}\right) / \mathrm{t}_{\mathrm{e}}
\end{aligned}
$$

where, is refers to the inner shell, gs refers to the gamma shielding, os refers to the outer shell, $r_{e}$ refers to the mean radius of the side wall, and $t_{e}$ refers to the thickness of the end wall. The resulting density for the end wall was $0.39978 \mathrm{lb} / \mathrm{in}^{3}$ for the rail cask and $0.58813 \mathrm{lb} / \mathrm{in}^{3}$ for the truck cask. 


\section{Material Models and Design Limits}

An elastic material model, an elastic-plastic material model with linear hardening, and a polyurethane foam model were utilized in this study for the materials listed in Table 3. For all materials, room temperature properties were assumed.

Table 3: Material Properties

\begin{tabular}{|l|l|l|l|l|l|l|}
\hline & E (ksi) & $v$ & $\begin{array}{c}\text { Yield } \\
(\mathrm{ksi})\end{array}$ & $\begin{array}{c}\text { Ultimate } \\
(\mathrm{ksi})\end{array}$ & $\mathrm{H}(\mathrm{ksi})$ & \multicolumn{1}{|c|}{$\begin{array}{l}\text { density } \\
\left(\mathrm{lb} / \mathrm{in}^{3}\right)\end{array}$} \\
\hline \hline SS 304L & 28,000 & 0.27 & 30 & 75 & 350 & 0.29 \\
\hline Lead & 2,400 & 0.44 & 1.1 & 2 & 5 & 0.412 \\
\hline $\begin{array}{l}\text { Depleted Ura- } \\
\text { nium (compr.) }\end{array}$ & 15,000 & 0.2 & 48 & 48 & 0 & 0.69 \\
\hline $\begin{array}{l}\text { Depleted Ura- } \\
\text { nium (tension) }\end{array}$ & 15,000 & 0.2 & 0 & 0 & 0 & 0.69 \\
\hline Neutron shield & & & & & 0 & 0.036 \\
\hline $\begin{array}{l}\text { Polyurethane } \\
\text { foam }\end{array}$ & 34 & 0.1 & 1.3 & - & 0.0116 \\
\hline Contents & 1,000 & 0.49 & 1.0 & - & 0.0 & 0.0612 \\
\hline
\end{tabular}

Depending on whether an elastic design criterion or an inelastic design criterion was used, a different material model was used for the structural stainless steel container: 304 stainless steel inner shell, outer shell, and end walls. A linear elastic material model was used for these components when using the elastic design criterion, whereas an elastic-plastic material model with linear hardening was used when using the inelastic design criterion, (see Figure 3).

The energy absorbing impact limiter was a "twenty-pound" polyurethane foam and was modelled using a foam model developed by Neilsen [2]. The model includes the effects of volumetric crush and lock-up. In addition to the parameters listed in Table 3, the foam has the properties: $\mathrm{p}_{0}=14.7 \mathrm{psi}, \phi=0.36$, and solid bulk modulus of $150 \mathrm{ksi}$.

The contents are a sludge-like material that behaves similar to an incompressible fluid. Consequently, it was modelled as an elastic perfectly plastic material with very little shear strength but with a high volumetric stiffness. It has a specific weight of 1.7 .

The gamma shielding was allowed to move relative to the inner and outer stainless steel shells. A contact surface with a coefficient of friction of 0.45 was used to model these interfaces. The gamma shielding was modelled as an elastic-plastic material with linear hardening, as shown in Table 3. 
The maximum allowable stresses are computed by the formulas specified by the NRC Regulatory Guide 7.6 [1] in the case of elastic analysis and the ASME Boiler and Pressure Vessel Code, Section III, Appendix F [3] for the case of the inelastic analysis. For the stainless steel material, the maximum allowable membrane plus bending stress was $70 \mathrm{ksi}$ for the elastic analysis, and $67.5 \mathrm{ksi}$ for the inelastic analysis, as shown in Figure 3. No design changes were made in the elastic analyses based on buckling according to the ASME Boiler and Pressure Vessel Code, Case N-284 [4].

These allowable stresses are engineering stresses which are based on the undeformed geometry of the structure. However the transient dynamic analysis techniques utilized in this study provide true stresses which are based on the deformed geometry of the structure. Therefore, in all analyses, the true stresses were converted to engineering stresses by dividing the von Mises stress by one plus the effective strain using a constant volume assumption [5]. For pure tension or compression this formula is exact; however, for a combined loading this formula is only an approximation. In order to conservatively estimate the engineering stress, a compressive (algebraically negative) effective strain was assumed so that the engineering stress is always greater than the true stress.

In all analyses, the stainless steel wall thicknesses were increased when the allowable stress was exceeded. When a change in the wall thickness was required, a replacement ratio of stainless steel to gamma shielding was used such that the shielding effectiveness was the same as that in the baseline cask. For the rail cask that uses lead as its gamma shielding, the replacement ratio was 1 part lead to 1.75 parts stainless steel, and for the truck cask that uses depleted uranium for its gamma shielding, the replacement ratio was 1 part depleted uranium to 3.0 parts stainless steel.

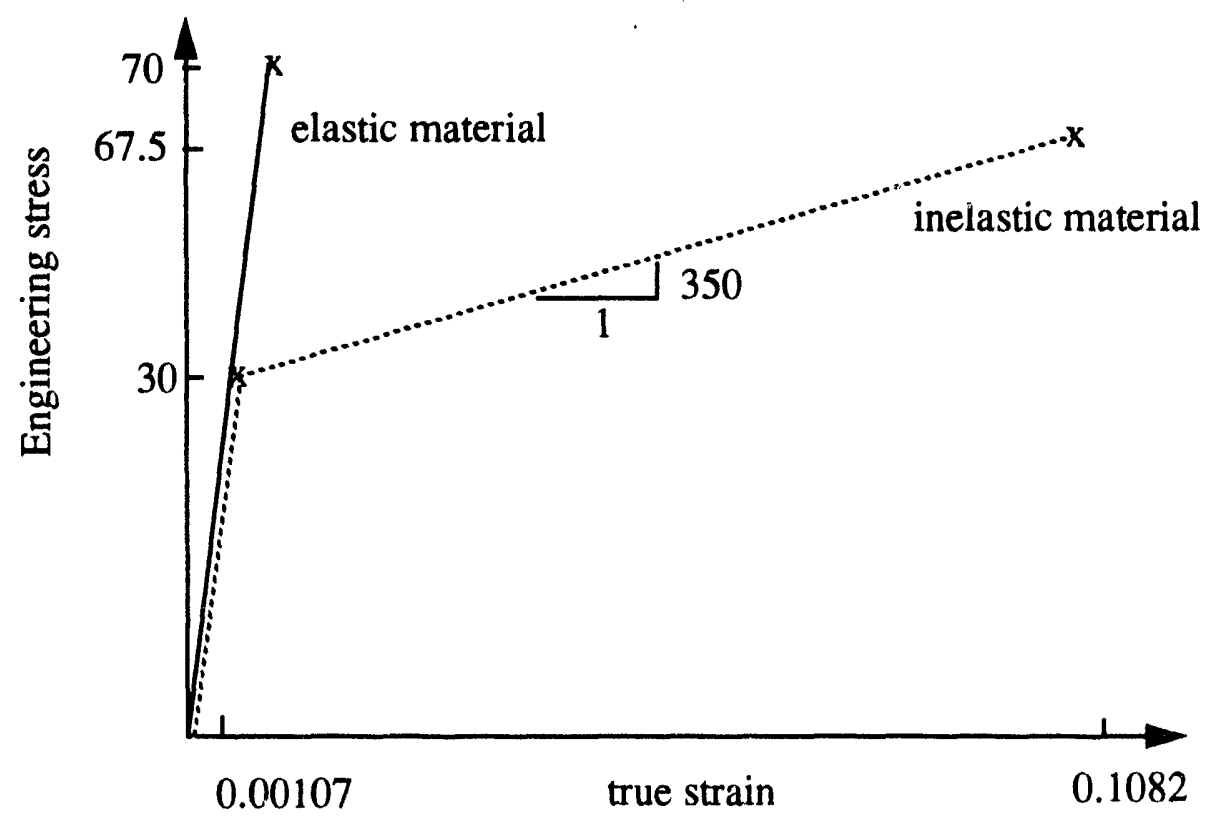

Figure 3. Engineering stress vs. true strain for 304 Stainless steel 


\section{End Impact}

\subsection{Finite element model}

The finite element models for the rail and truck RAM transportation package $30 \mathrm{ft}$. end impact scenarios are shown in Figure 4. In the following designs, a cask with completely full contents and one with nearly full contents are considered for an end impact. The purpose for considering different content levels is to determine any difference in the response of the cask.

The gamma shielding was allowed to slide within the inner and outer 304 stainless steel shells. Likewise the contents were allowed to push on and freely slide against the inner shell. The cask end wall was also modelled separately; however, no detail of the fastening between the end wall and the side wall was modelled. Instead the cask end wall was fixed against the side wall. The impact limiters were fixed against the end and were free to slide against the side walls.

The rail cask was modelled axisymmetrically with a total of 23054 elements with five elements through the thickness of the inner shell and five elcments through the thickness of the outer shell. Likewise, the truck cask was modelled axisymmetrically with a total of 26059 elements with five elements through the thickness of both the inner shell and outer shell. This degree of refinement was more than adequate to model any potential bending of the relatively thin inner and outer shells. All analyses for the end drop were performed with a transient dynamic analysis technique using the SNL code PRONTO2D [6].
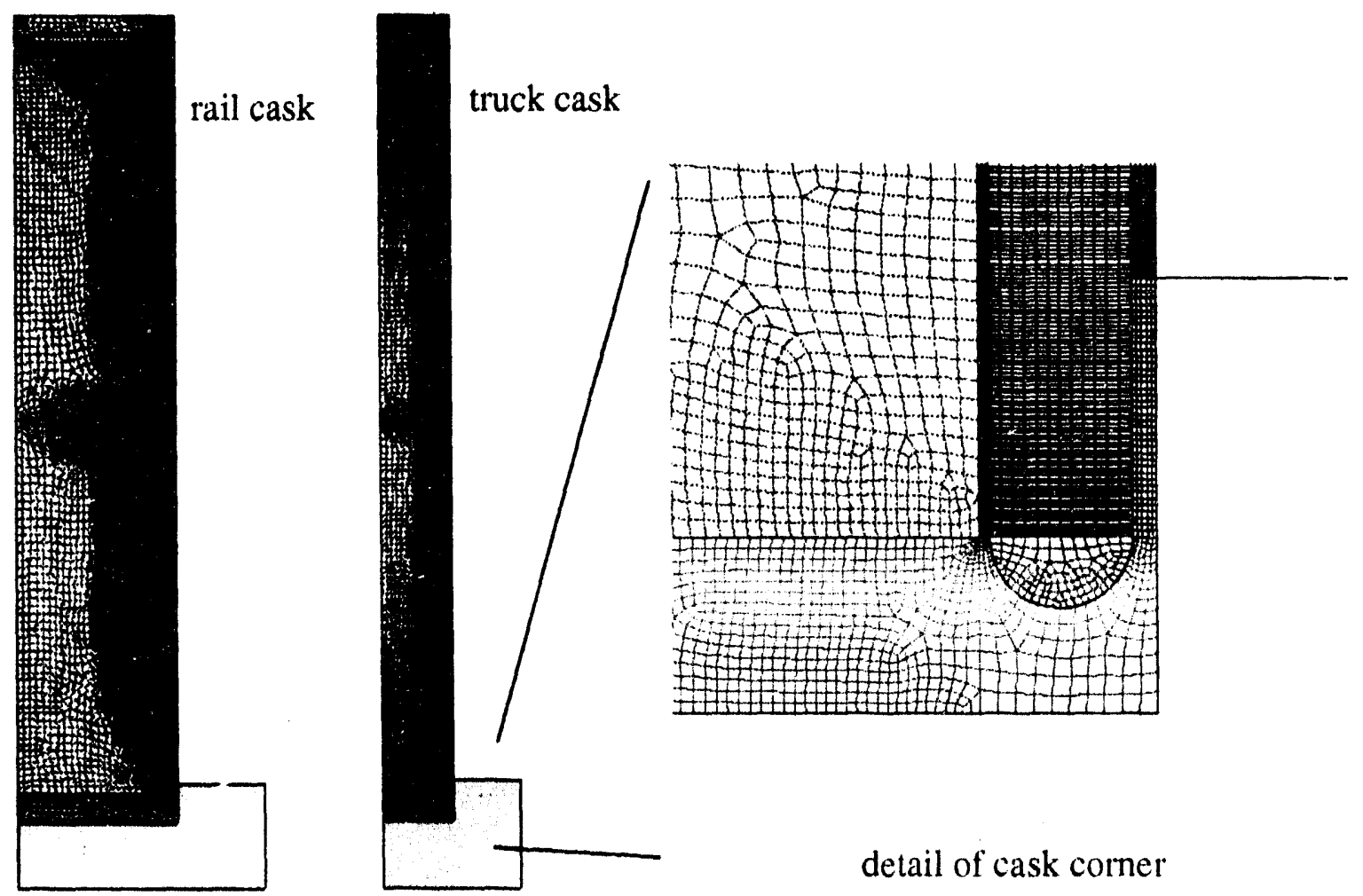

Figure 4. Finite element models for the rail and truck RAM transportation package for $30 \mathrm{ft}$. end impact scenario 


\subsection{Elastic design of rail cask}

In the elastic design, the baseline rail cask with completely full contents and one with nearly full contents are considered for an end impact. The impact was modelled as a dynamic event with initial velocity of $527.45 \mathrm{in} / \mathrm{s}$ corresponding to a $30 \mathrm{ft}$ end drop. The entire end drop event occurs over a time of approximately $\mathbf{4 0}$ milliseconds from the initial cask impact to cask rebound. Figure 5 shows the deformed shape of the rail cask with elastic inner and outer stainless steel shells and elastic stainless steel end walls. The contents, which were nearly full for the case shown in Figure 5, do not noticeably deform. In fact, the only noticeable deformation is a slight amount of gamma (lead) shielding slump and the crush of the impact limiter.

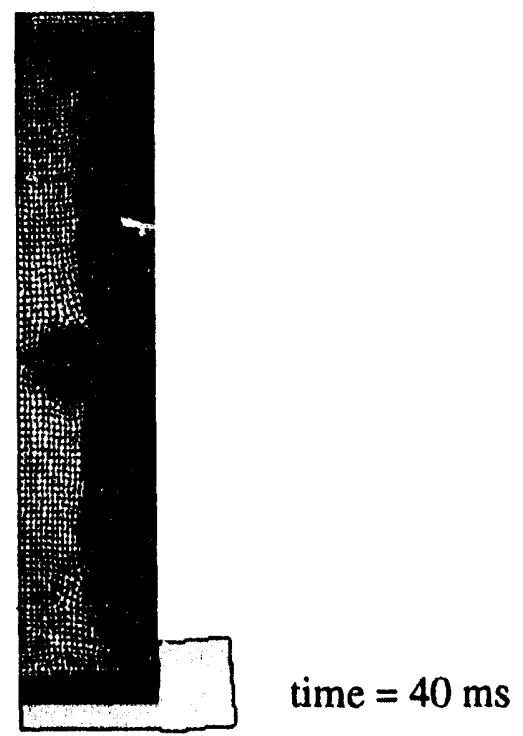

Figure 5. Deformed elastic rail cask after $30 \mathrm{ft}$. end drop

Figure 6 shows the maximum von Mises stress occurring in the two elastic casks. The cask with the completely full contents experiences a maximum von Mises stress of $40.06 \mathrm{ksi}$ in the outer shell at approximately 27.2 milliseconds. This maximum stress appears to be a result of the lead slumping and expanding near the impacted end. During the impact event, it was noticed that a large amount of the top lid's inertia and impact load is transferred to the contents. This significantly reduced the loading on the inner and outer shells.

The cask with the nearly full contents experiences a completely different loading history. The maximum von Mises stress is $81.82 \mathrm{ksi}$ and occurs in the inner shell at a much earlier time of 11.3 milliseconds. The von Mises stress is a result of the combined compressive loading on the shell and the lead shielding bending the inner shell. The lid does not impact the contents during the event for the cask with the nearly full contents. This requires that the inner and outer shells support the complete impact load of the lid and their self-weight. For this reason, it appears that a cask with nearly full contents represents a more severe end impact event.

The maximum (engineering) stress of $81.82 \mathrm{ksi}$ is above the maximum allowable combined membrane and bending stress of $70 \mathrm{ksi}$. The baseline rail cask was therefore redesigned based on the elastic design criteria. The cedesign involved increasing the inner shell thickness to 0.36 inches and changing the gammd shielding to 5.946 inches to remain at the same shielding 
effectiveness. In the end impact simulation of the redesigned cask, the maximum von Mises stress was $71.9 \mathrm{ksi}$, as shown in Figure 7. This level of stress just exceeds the allowable stress according to the elastic design criteria allowing a maximum combined membrane and bending stress of $70 \mathrm{ksi}$.

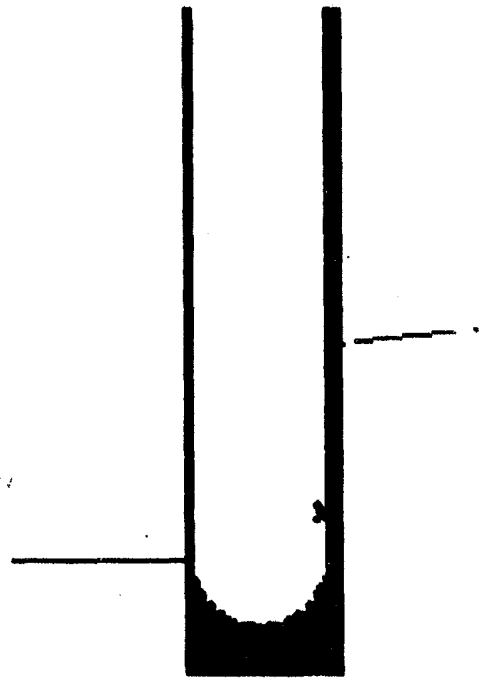

(a) contents full von Mises

stress

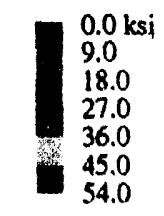

$* 40.06 \mathrm{ksi}$

time $27.2 \mathrm{~ms}$

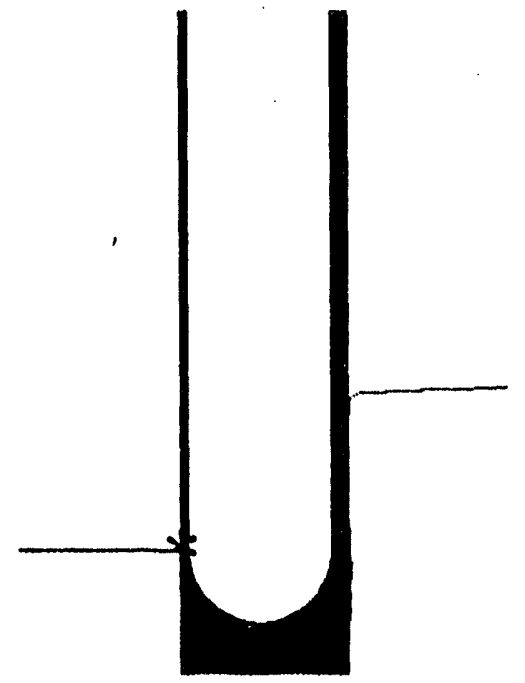

(b) contents nearly full von Mises

stress

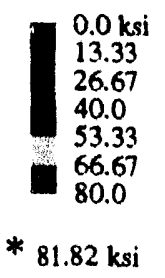

time $11.3 \mathrm{~ms}$

Figure 6. Maximum von Mises stress during the $30 \mathrm{ft}$. end drop of elastic rail cask
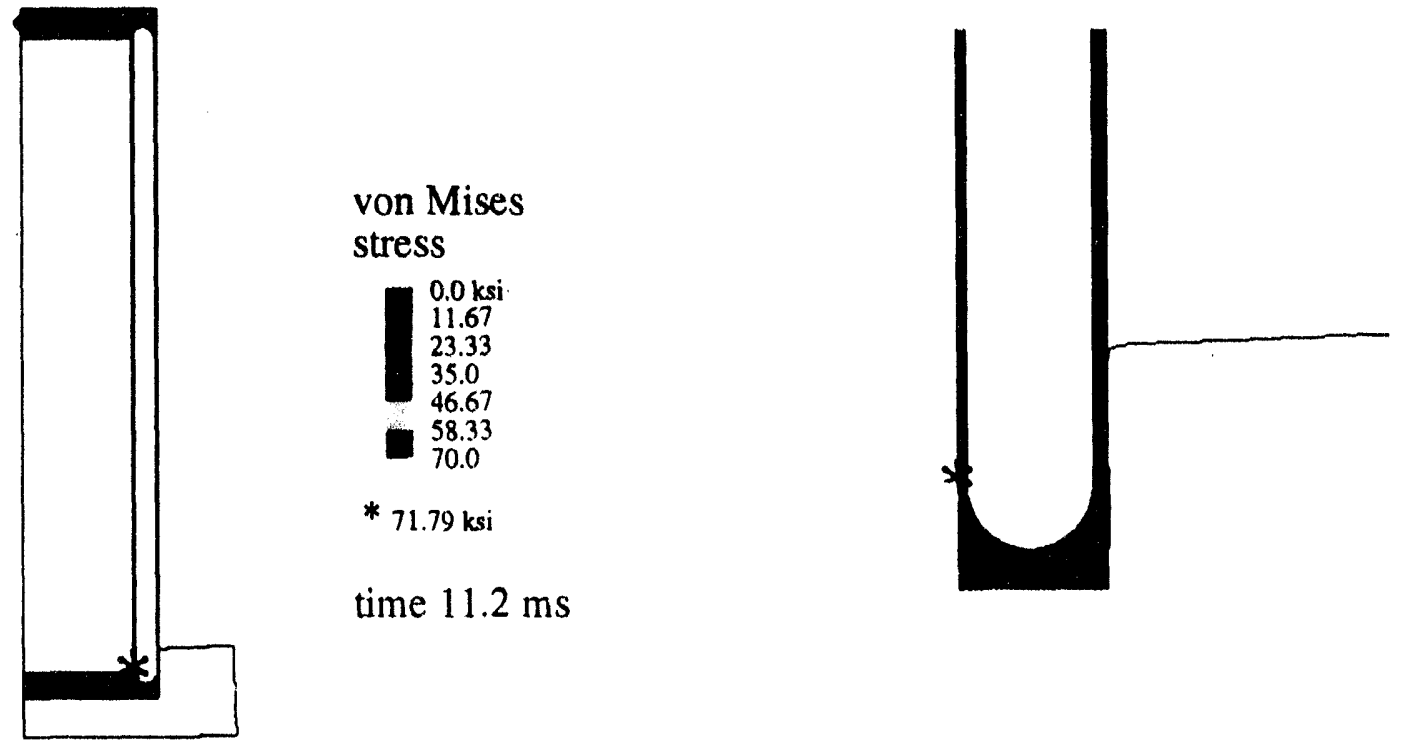

time $11.2 \mathrm{~ms}$

von Mises

stress

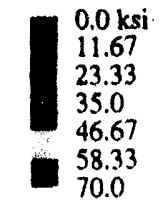

* $71.79 \mathrm{ksi}$

Figure 7. Maximum von Mises stress in the redesigned elastic rail cask during $30 \mathrm{ft}$. end drop (contents nearly full)

\subsection{Inelastic design of rail cask}

The $30 \mathrm{ft}$. end drop impact was modelled as a dynamic event with the same initial velocity of $527.45 \mathrm{in} / \mathrm{s}$. In the following design, an inelastic cask with completely full contents and one with nearly full contents are considered for an end impact. The deformed shape of the rail cask. 
shown in Figure 8, is for a cask with nearly full contents. Its deformed shape is indistinguishable from a deformed cask with completely full contents.

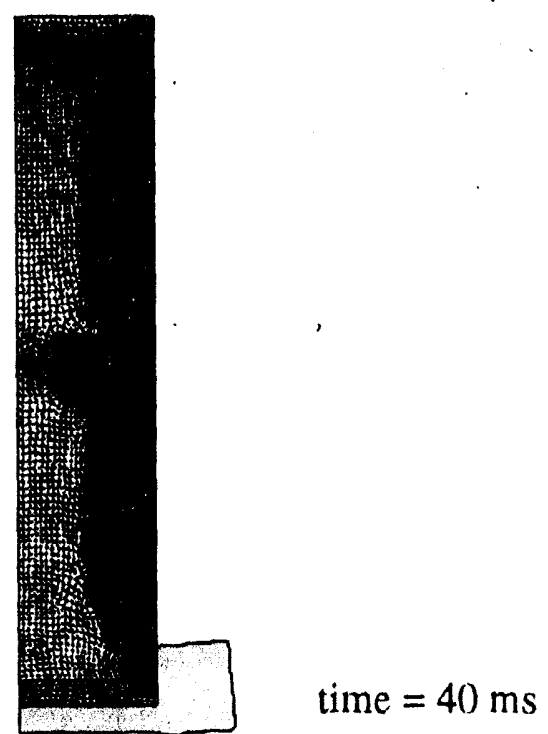

Figure 8. Deformed inelastic rail cask after $30 \mathrm{ft}$. end drop

Figure 9 shows the maximum von Mises stress occurring in the two casks during impact (up until the maximum g-loading at approximately 30 milliseconds). In the inelastic analysis of the cask with completely full contents, the maximum von Mises stress was $30.57 \mathrm{ksi}$ in the outer shell. This maximum stress occurs at approximately 21.2 milliseconds into the impact. The cask with the nearly full contents experiences a von Mises stress of $32.13 \mathrm{ksi}$ in the inner shell during impact. The yielding of the inner shell results in load redistribution to the gamma shielding and outer shell. The permanent (equivalent plastic) strain distribution in the nearly full cask resulting from the inelastic behavior is shown in Figure 10.

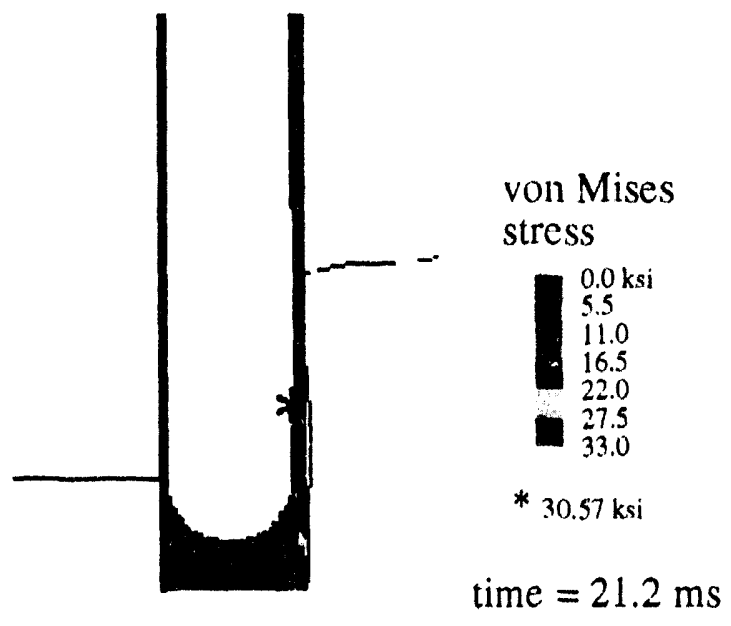

(a) contents full

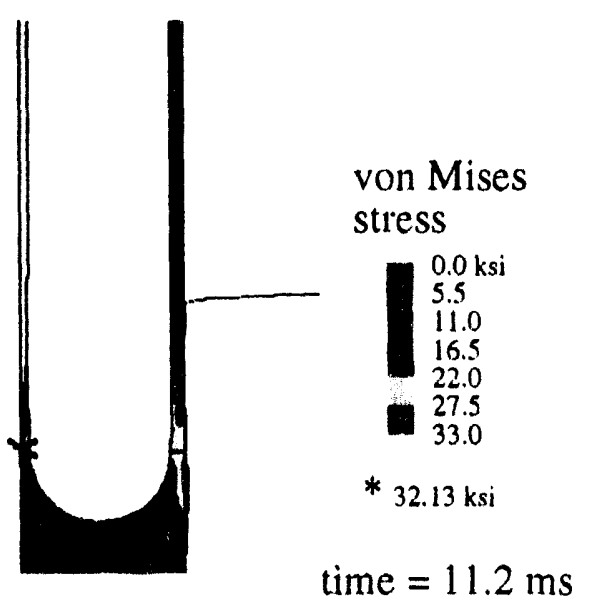

(b) contents nearly full

Figure 9. Maximum von Mises stress during the $30 \mathrm{ft}$. end drop of inelastic rail cask 


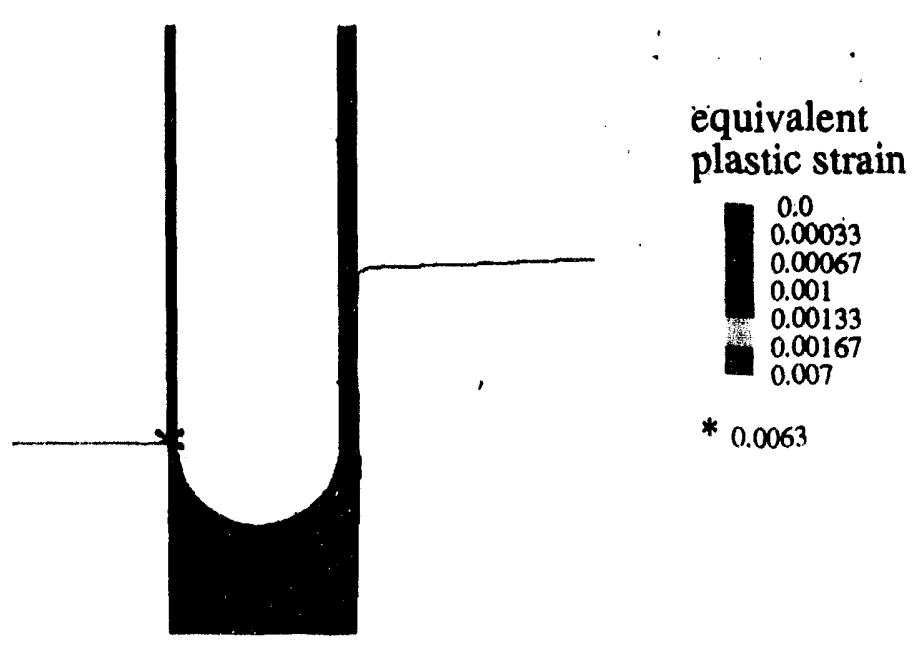

Figure 10. Maximum equivalent plastic strain in the inelastic rail cask

After the container experiences the maximum g-loading (at approximately 30 milliseconds), it rebounds and reverses the loading on the inner and outer shells. Because of the stored strain energy remaining in the structure, the stress levels during rebounding can be higher than those found during the impact. Such was the case in this particular example, resulting in a maximum von Mises stress of $32.57 \mathrm{ksi}$, as shown in Figure 11. However, the maximum von Mises stresses, for both the full and nearly full casks during impact and rebound, are well below the maximum allowable stress of $67.5 \mathrm{ksi}$.
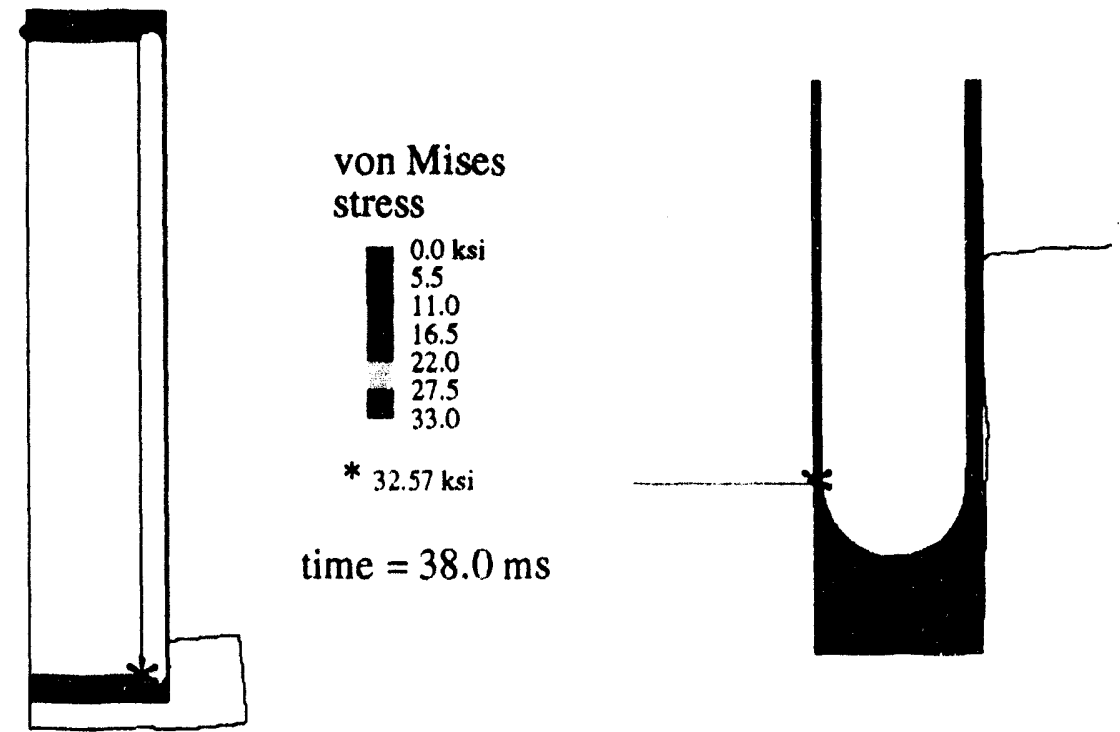

Figure 11. Maximum von Mises stress after rebound of inelastic rail cask subjected to $30 \mathrm{ft}$. end impact (contents nearly full) 


\subsection{Comparison of elastic and inelastic design of rail cask}

Figure 12 shows the kinetic energy and g-loading histories during the end drop scenario for both the elastic and inelastic rail cask with nearly full contents. The g-loading was computed by summing the mass times acceleration at all the nodal points in the cask. Both the kinetic energy and g-loading are representative of the overall body's behavior during the impact event. While these results appear nearly identical, major differences still occur in the predicted stress histories of the two casks.
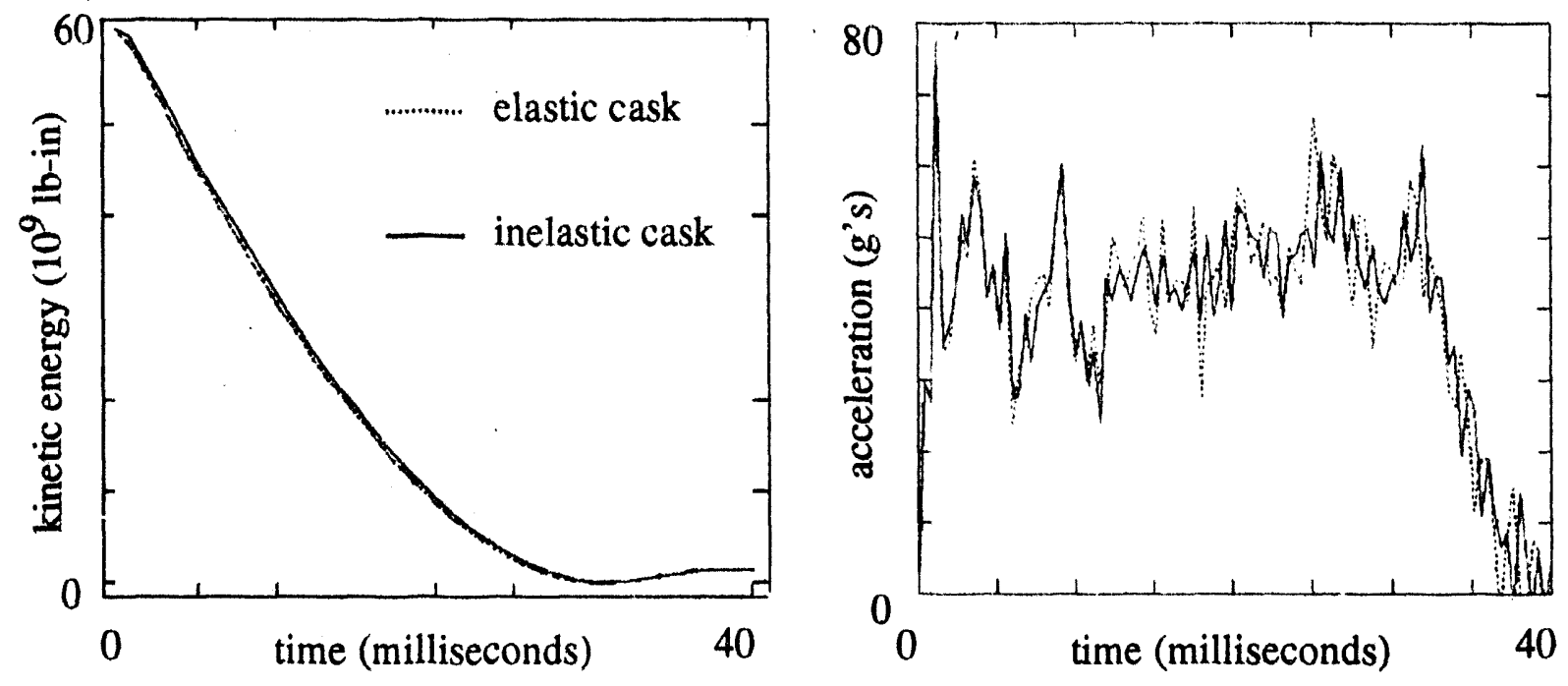

Figure 12. Kinetic energy and G-loading history for elastic and inelastic rail cask subjected to $30 \mathrm{ft}$ end drop

To illustrate this point, it is informative to look at the stress histories in the shells for the elastic and inelastic analyses of the nearly full cask. Figure 13 shows the locations, A and B, where the maximum von Mises stress occurs in both shells.

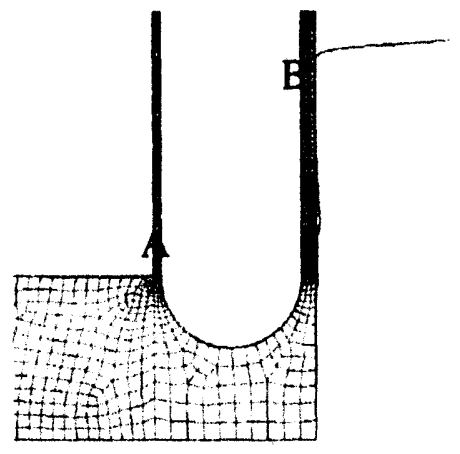

Figure 13. Inner and outer shell locations in the nearly full cask where maximum von Mises stress occurs

The von Mises stress history for location A is shown in Figure 14 for both the elastic cask and the inelastic cask. To give an idea of the stress level in the region of the inner shell (called location A), two element stress histories are plotted. These two elements are those where the maximum von Mises stress occurs during the impact in the inner shell. It is clear from these results that both the magnitude and timing of the stress are different for elastic and inelastic 
casks. In the elastic cask, the maximum stress is $81.88 \mathrm{ksi}$ at 11.3 milliseconds, whereas in the inelastic cask the maximum stress is $32.57 \mathrm{ksi}$ and occurs at 38 . milliseconds. Because of the residual stresses remaining in the inelastic structure after impact, the stress levels during rebounding are higher.

Figure 15 shows the stress histories for several elements in location B for the elastic and inelastic casks. The elements are in the location where the maximum von Mises stress occurs in the outer shell. The magnitudes of the stress are significantly different.

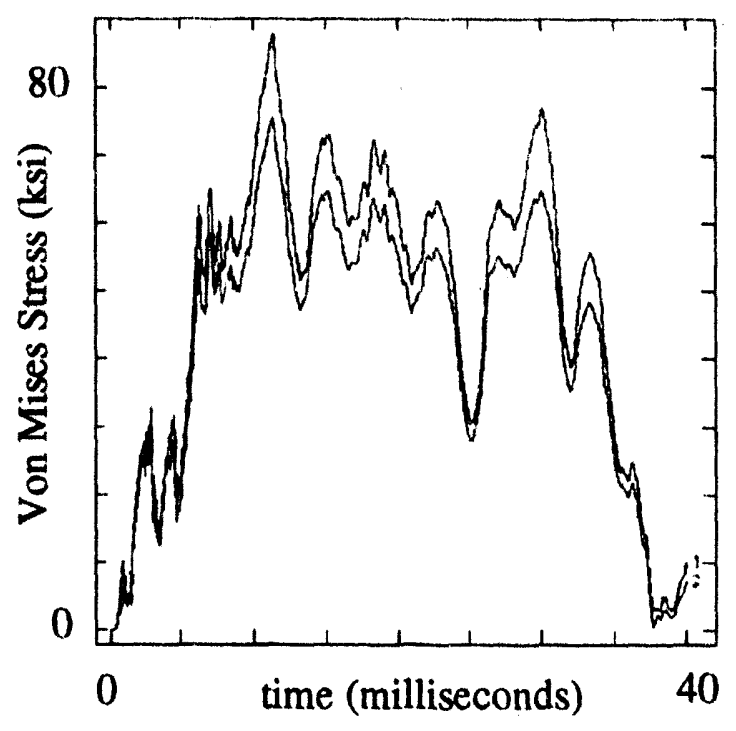

(a) elastic cask

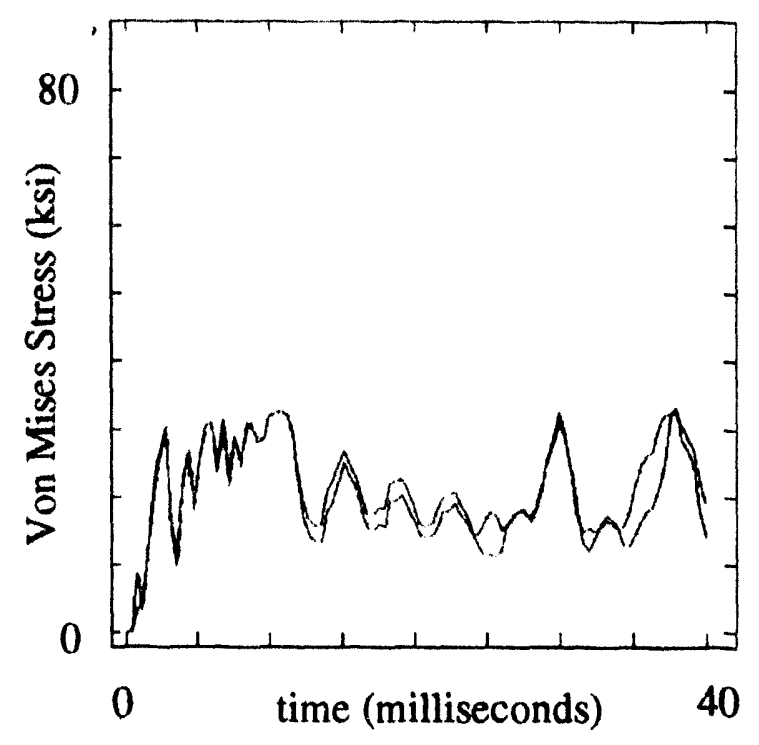

(b) inelastic cask

Figure 14. Von Mises stress history for two elements at location $A$ on the inner shell of the nearly full cask

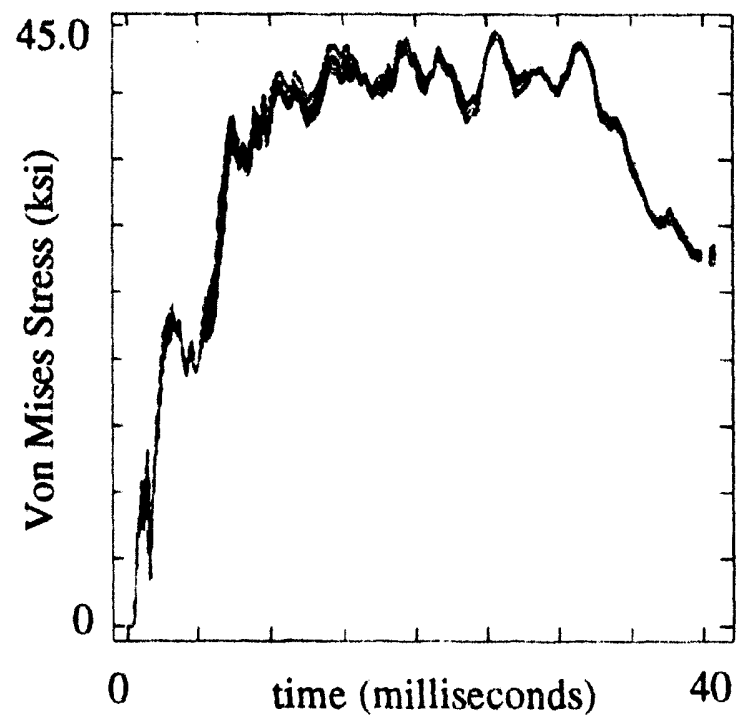

(a) elastic cask

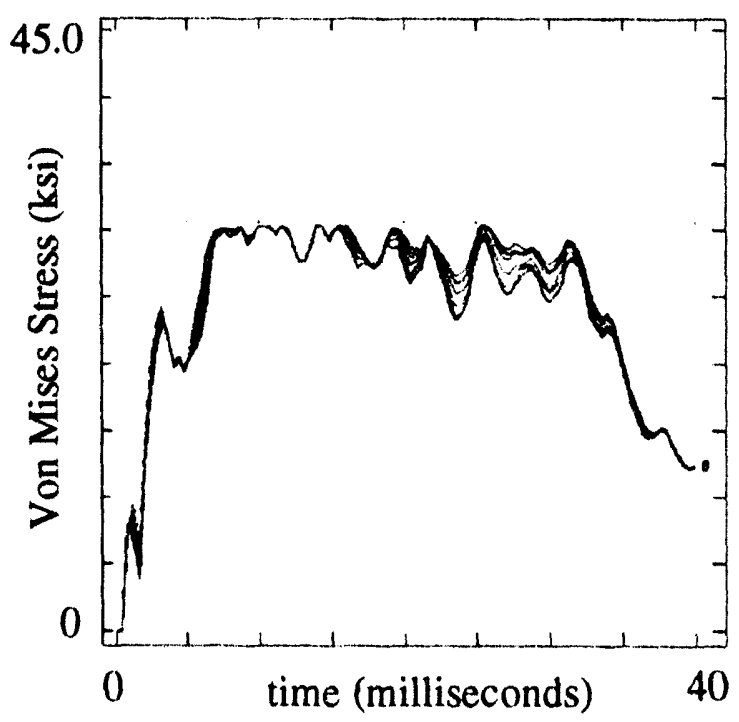

(b) inelastic cask

Figure 15. Von Mises stress history for several elements at location B on the outer shell of the nearly full cask 


\subsection{Elastic design of truck cask}

The design of the truck cask considered a full and a nearly full cask. The $30 \mathrm{ft}$. end impact of the nearly full cask was modelled as a dynamic event with initial cask velocity of $527.45 \mathrm{in} / \mathrm{s}$. Figure 16 shows the deformed shape of the truck cask with elastic inner and outer stainless steel shells and elastic stainless steel end walls. The entire end drop event occurs over a time of approximately 40 milliseconds from initial cask impact to rebound:The maximum von Mises stress for a full and nearly full elastic cask are shown in Figure 17. For the full cask, the cask experienced a maximum stress of $43.4 \mathrm{ksi}$, occurring in the inner shell at 31.3 milliseconds. For the nearly full cask, the cask experienced a maximum stress of $45 \mathrm{ksi}$, also occurring in the inner shell but at a time of 23.6 milliseconds.

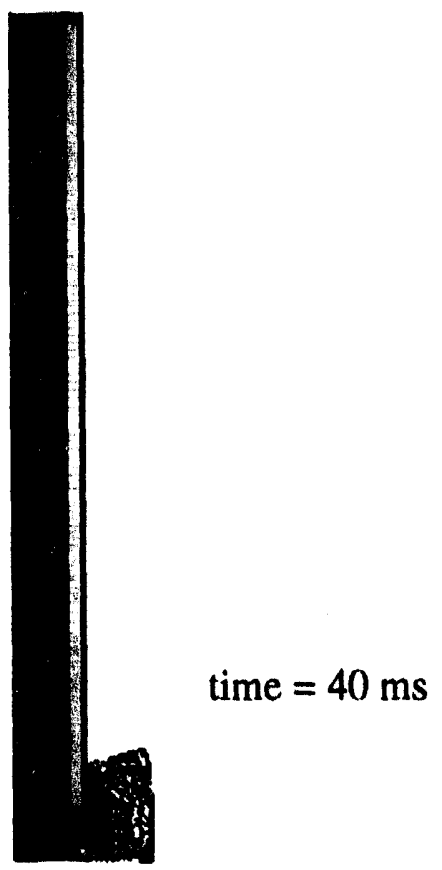

Figure 16. Deformed elastic truck cask after $30 \mathrm{ft}$. end drop

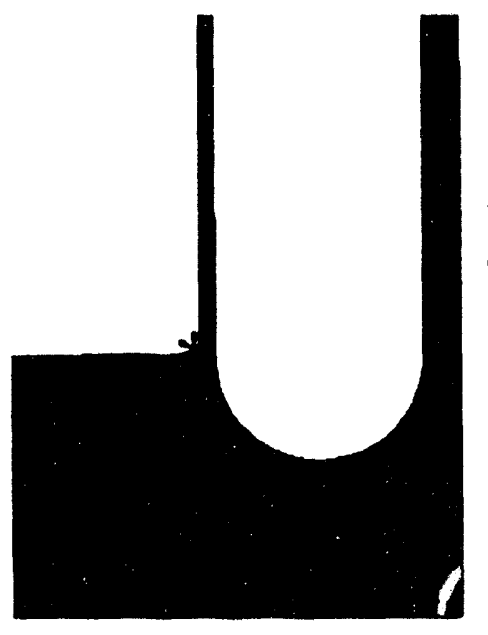

(a) full contents

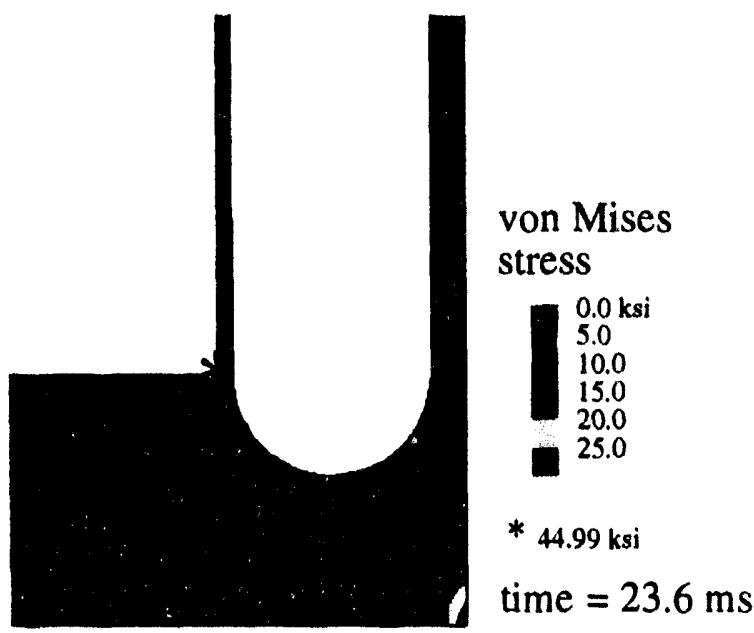

(b) nearly full contents

Figure 17. Maximum von Mises stress during the $30 \mathrm{ft}$. end drop of elastic truck cask with contents full and nearly full 
In the truck cask, the fact that the contents are full or nearly full make much less of a difference since the depleted uranium gamma shielding is much stiffer and absorbs a considerable amount of the lid's momentum during impact. For this reason, the maximum predicted von Mises stresses in the full and nearly full casks are nearly identical.

\subsection{Inelastic design of truck cask}

The $30 \mathrm{ft}$. end drop impact of the inelastic cask was also modelled as a dynamic event with initial velocity of $527.45 \mathrm{in} / \mathrm{s}$. Figure 18 shows the deformed shape of the truck cask for the inelastic analysis, where the only noticeable deformation occurs in the impact limiter. For the full cask, the maximum von Mises stress of $30.4 \mathrm{ksi}$ occurred in the inner shell during impact at 23.5 milliseconds, as shown in Figure 19.

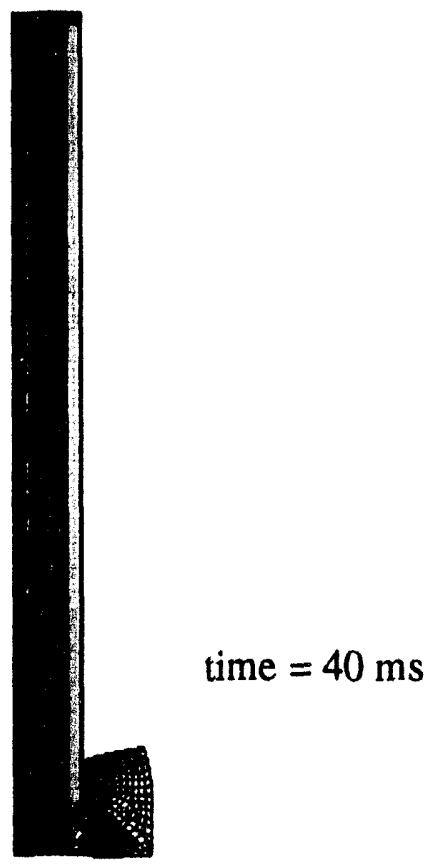

Figure 18. Deformed inelastic truck cask after $30 \mathrm{ft}$. end drop

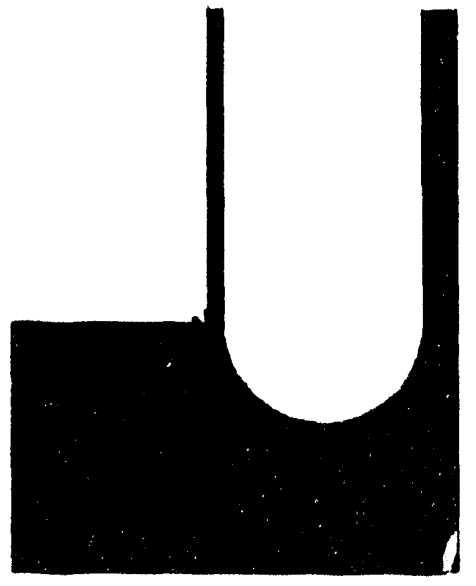

(a) full contents

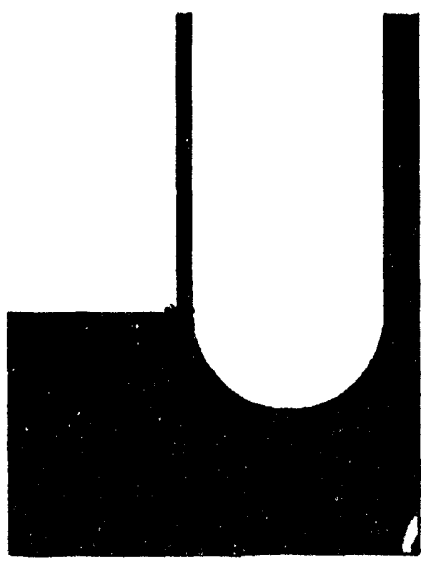

(b) nearly full contents von Mises

stress

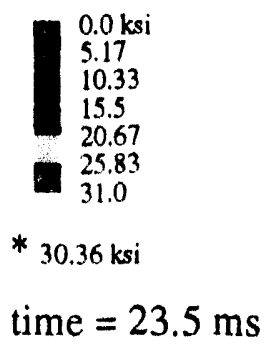

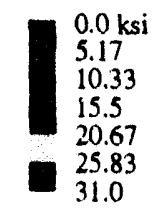

* $30.75 \mathrm{ksi}$

time $=23.8 \mathrm{~ms}$

Figure 19. Maximum von Mises stress in the cask shells during $30 \mathrm{ft}$ end impact of inelastic truck cask with contents full and nearly full 
For the nearly full cask, the maximum von Mises stress of $30.8 \mathrm{ksi}$ also occurred in the inner shell and occurs almost at the same time. The predicted location of maximum von Mises stress is about the same as that in the elastic cask; however, the magnitude of stress is much smaller. The smaller maximum predicted von Mises stress in the inelastic analysis relative to the elastic cask is qualitatively identical to that observed in the design of the rail cask. This large difference between the predicted maximum von Mises stress in the elastic and inelastic analysis is due to the plastic deformation in the stainless steel shells. Figure 20 shows the maximum equivalent plastic strain corresponding to the maximum von Mises stress. The maximum plastic strain of 0.002254 results in a rather large difference in maximum von Mises stress.
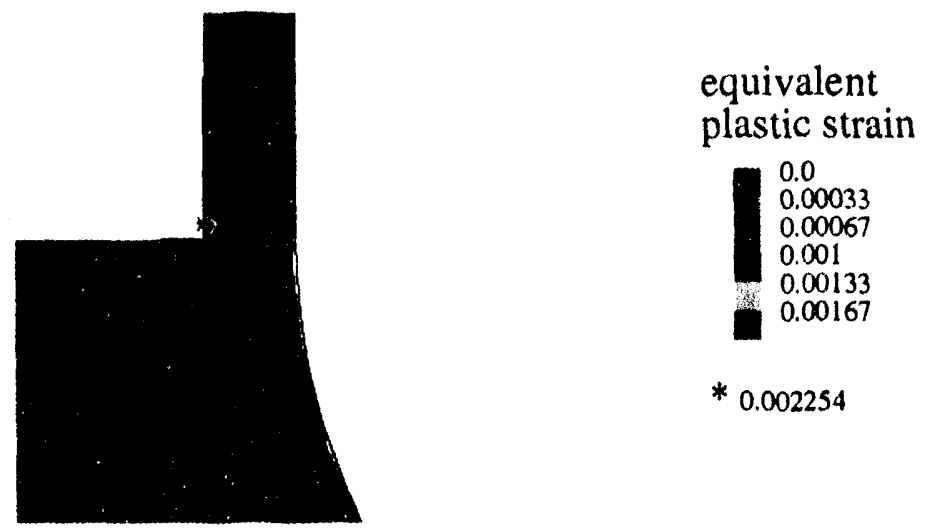

Figure 20. Equivalent plastic strain in the inner shell of inelastic truck cask

\subsection{Comparison of elastic and inelastic design of truck cask}

Figure 21 and Figure 22 show the kinetic energy and g-loading histories during the end drop scenario for both the elastic and inelastic truck cask. The kinetic energy and g-loading histo-

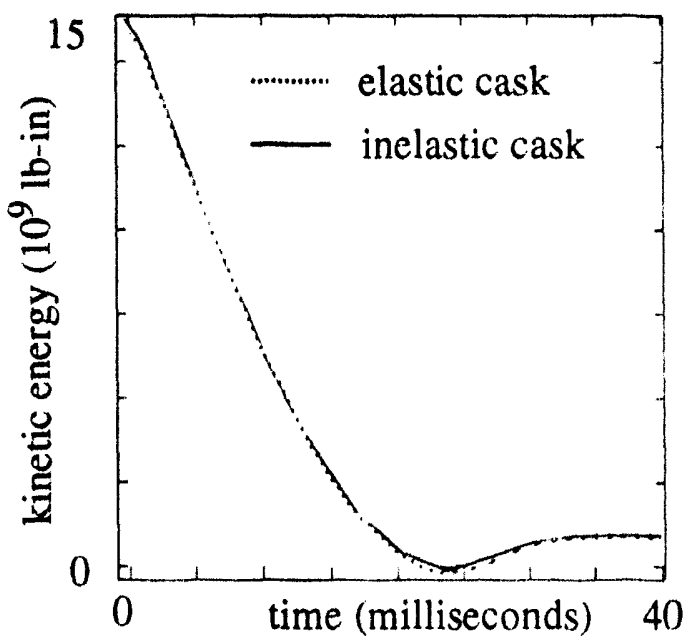

Figure 21. Kinetic energy history for elastic and inelastic truck cask subjected to $30 \mathrm{ft}$ end drop

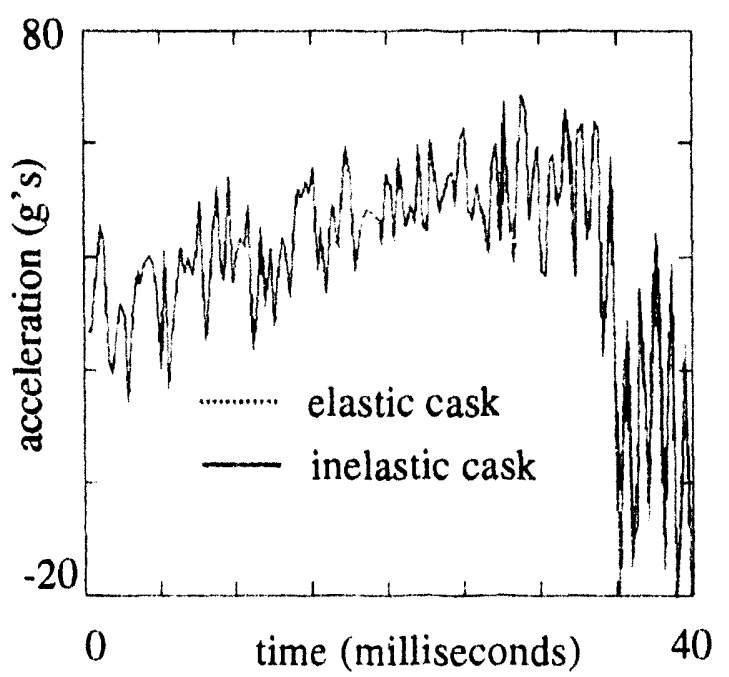

Figure 22. G-loading history for elastic and inelastic truck cask subjected to $30 \mathrm{ft}$. end drop 
ries for the full and nearly full cask are identical, so that the following comparison between the elastic and inelastic cask subjected to the 30 foot end impact does not depend on whether the contents are full or nearly full.

The kinetic energy and g-loading appear nearly identical but are only representative of the body's overall behavior during the impact event. In fact, the predicted maximum von Mises stress and time of occurrence in the elastic and inelastic casks are different. The maximum von Mises stress in the elastic cask occurred during impact, whereas it occurred after the impact during the rebounding in the inelastic cask. Furthermore, the inelastic analysis shows that a significant amount of plastic straining occurs in both the inner and outer shell. This added information provides a better qualitative understanding of the impact event. 


\section{Side Impact}

\subsection{Finite element model}

The finite element models for the rail and truck RAM transportation package $30 \mathrm{ft}$. side drop scenarios are shown in Figure 23. Only a quadrant of the entire cask was modelled due to double symmetry. The baseline rail cask dimensions are the same as those in Table 1 with the following exceptions: inner shell thickness $=0.36$ in., gamma shielding thickness $=5.9457$ in., outer shell thickness $=0.6$ in. These dimensions reflect the redesign of the elastic rail cask to satisfy the elastic design criterion. The redesigned cask was used for both the elastic and inelastic side impact analyses so that more meaningful comparisons could be made.

The components were modelled separately so that the gamma shielding was allowed to slide within the inner and outer 304 stainless steel shells. Likewise the contents were allowed to push and freely slide against the inner shell. The cask end wall was also modelled separately. However, no detail of the fastening between the end wall and the side wall was modelled. Instead, the cask end wall was fixed against the side wall. The impact limiters were also fixed in this manner against the end and side walls.

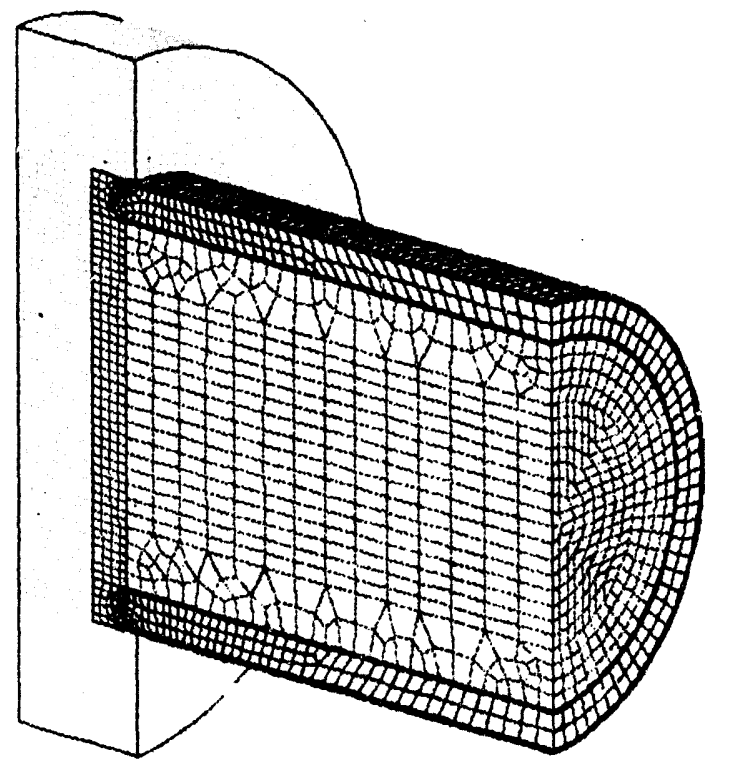

rail cask

detail of cask corner

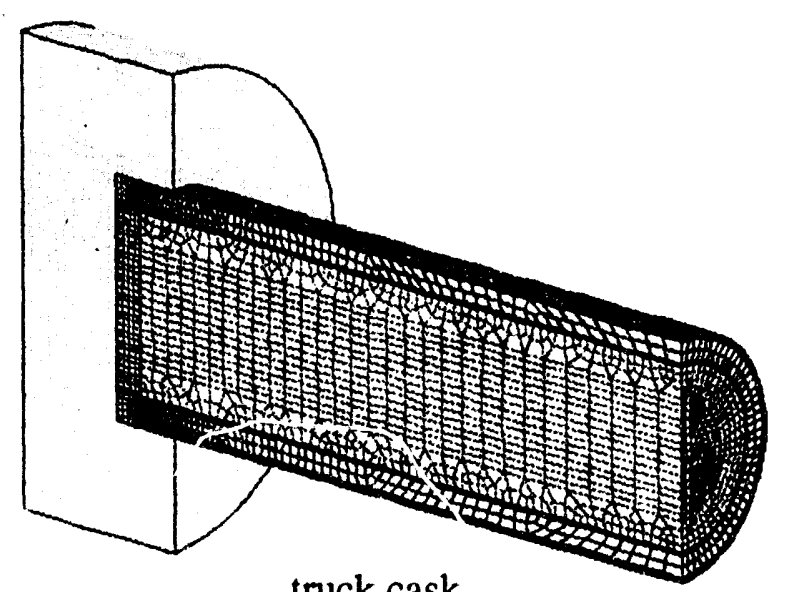

truck cask

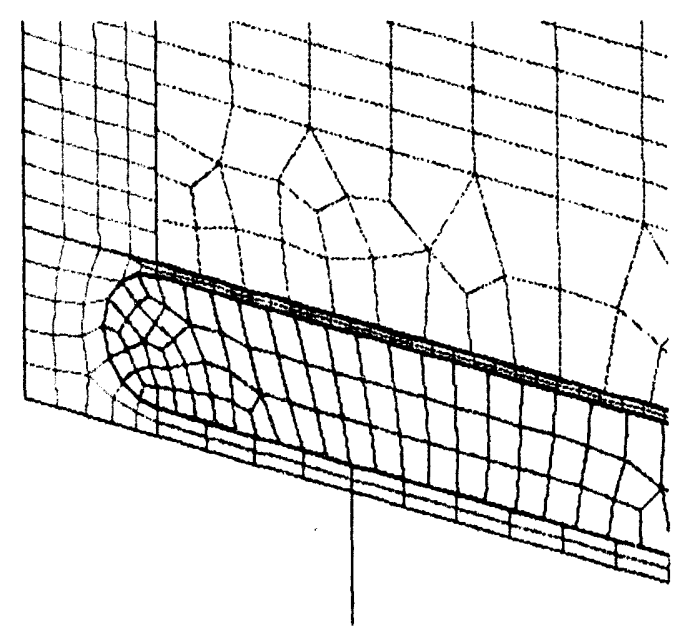

Figure 23. Finite element models for the rail and truck RAM transportation package $30 \mathrm{ft}$. end drop scenario 
The rail cask was modelled with a total of 39912 elements with two elements through the thickness of the inner shell and two elements through the thickness of the outer shell. Likewise, the truck cask was modelled with a total of 44360 elements with two elements through the thicknesses of the inner and outer shells. It is noted that two elements through the thickness is not enough to accurately capture the magnitude of the bending stresses in the shell walls. However, due to the large amounts of CPU time required for more detailed predictions, the number of elements through the thickness of the shells was limited to two. The qualitative nature of the comparisons presented here should not change even if more elements were used. For the side impact analyses, only a cask with full contents was considered. This is due to the observation that orientation of the impact event has a role in the interaction between the cask and the contents. In the side drop, the amount of material above the void created by a nearly full cask would be insignificant and not affect the loading history. Therefore, the question of full or nearly full contents is not an issue for both the side impact events and the center-ofgravity-over-corner impacts. In all side impacts and center-of-gravity-over-corner impacts that follow, only a cask with full contents was considered. The transient dynamic code PRONTO3D [7] was used in all analyses.

\subsection{Elastic design of rail cask}

The impact was modelled as a dynamic event with initial velocity of $527.45 \mathrm{in} / \mathrm{s}$ corresponding to a $30 \mathrm{ft}$. side drop. Figure 24 shows the deformed shape of the rail cask with elastic inner and outer stainless steel shells and elastic stainless steel end walls. The only noticeable deformation occurs in the impact limiter that crushes while absorbing energy during the event. The entire end drop event occurs over a time of approximately 80 milliseconds from initial cask impact to rebound.

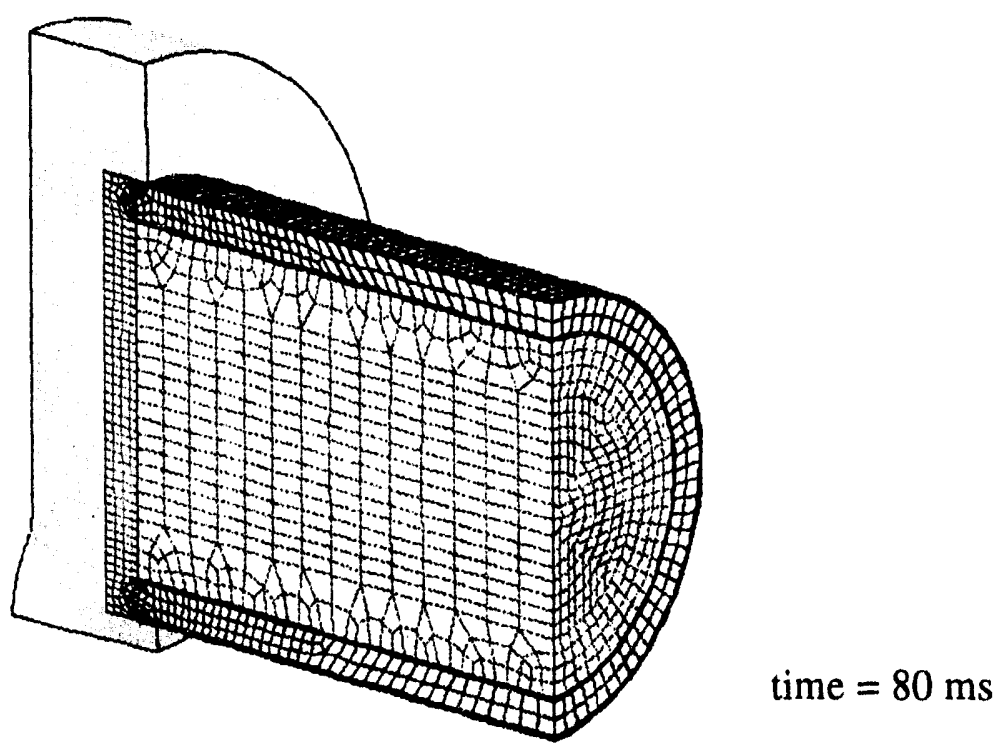

Figure 24. Deformed elastic rail cask after $30 \mathrm{ft}$. side drop

The maximum von Mises stress was $49.9 \mathrm{ksi}$ at 51.2 milliseconds which corresponds to occurrence of the maximum g-loading on the cask. The location of this maximum stress, denoted by the star, was in the inner shell as shown in Figure 25. This seems to be a direct result of the 
inner shell carrying the majority of the inertial load of the contents. Because of the lower stiffness of the lead shielding, less of the inertial load is transferred to the outer shell. Instead, the stresses in the outer shell are due mostly to the overall bending of the rail cask.

The maximum combined membrane and bending engineering stress of $50.0 \mathrm{ksi}$ is below the maximum allowable combined membrane and bending stress of $70 \mathrm{ksi}$. The rail cask design is therefore acceptable based on the elastic design criteria for the side drop.
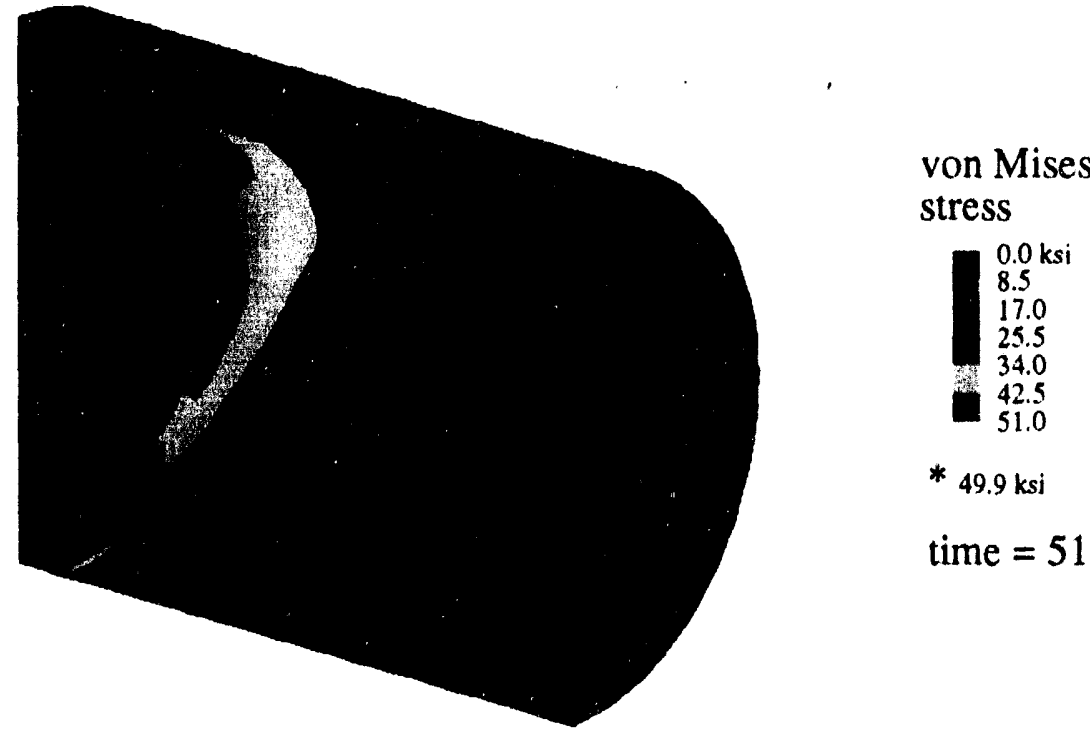

* $49.9 \mathrm{ksi}$

time $=51.2 \mathrm{~ms}$

Figure 25. Maximum von Mises stress during the $30 \mathrm{ft}$. side drop of elastic rail cask

\subsection{Inelastic design of rail cask}

Figure 26 shows the deformed shape of the inelastic rail cask subjected to a $30 \mathrm{ft}$. side drop impact with initial velocity of $527.45 \mathrm{in} / \mathrm{s}$. Again, the only noticeable deformation occurs in the impact limiter due to volumetric crushing.

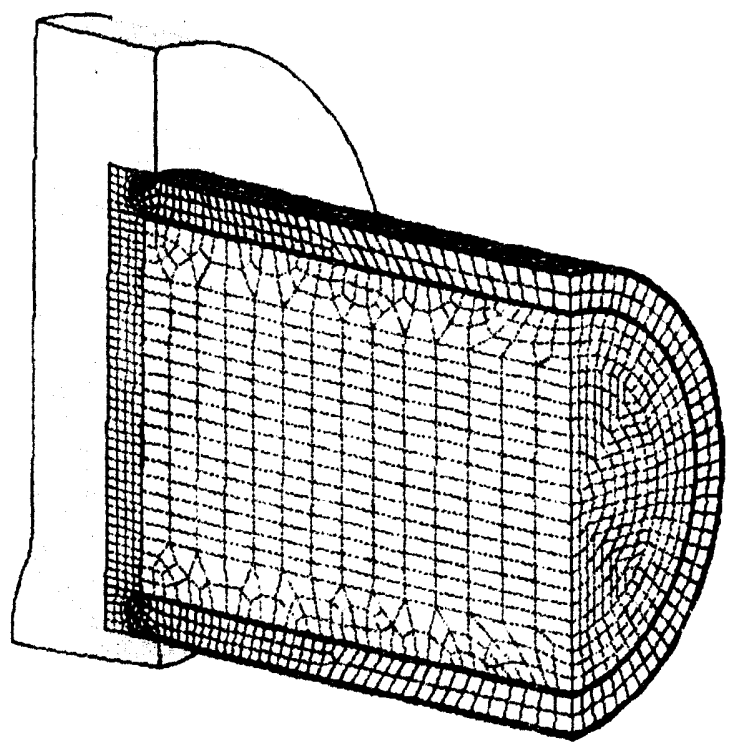

time $=80 \mathrm{~ms}$

Figure 26. Deformed inelastic rail cask after $30 \mathrm{ft}$.side drop 
The maximum von Mises stress of $32.52 \mathrm{ksi}$ occurred in the inner shell at approximately $\mathbf{4 3 . 2}$ milliseconds. Because the stainless steel is allowed to yield, the maximum von Mises stress in the inner shell is considerably less than that found in the elastic analysis. The permanent equivalent plastic strain corresponding to the inelastic deformations is shown in Figure 28. The plastic deformation is local to a region near the cask end wall and appears to be caused by shear stresses that have caused yielding. The importance of modelling the steel's ability to permanently plastically deform is evident from the significantly different predicted maximum stresses between the elastic analysis and inelastic analysis.

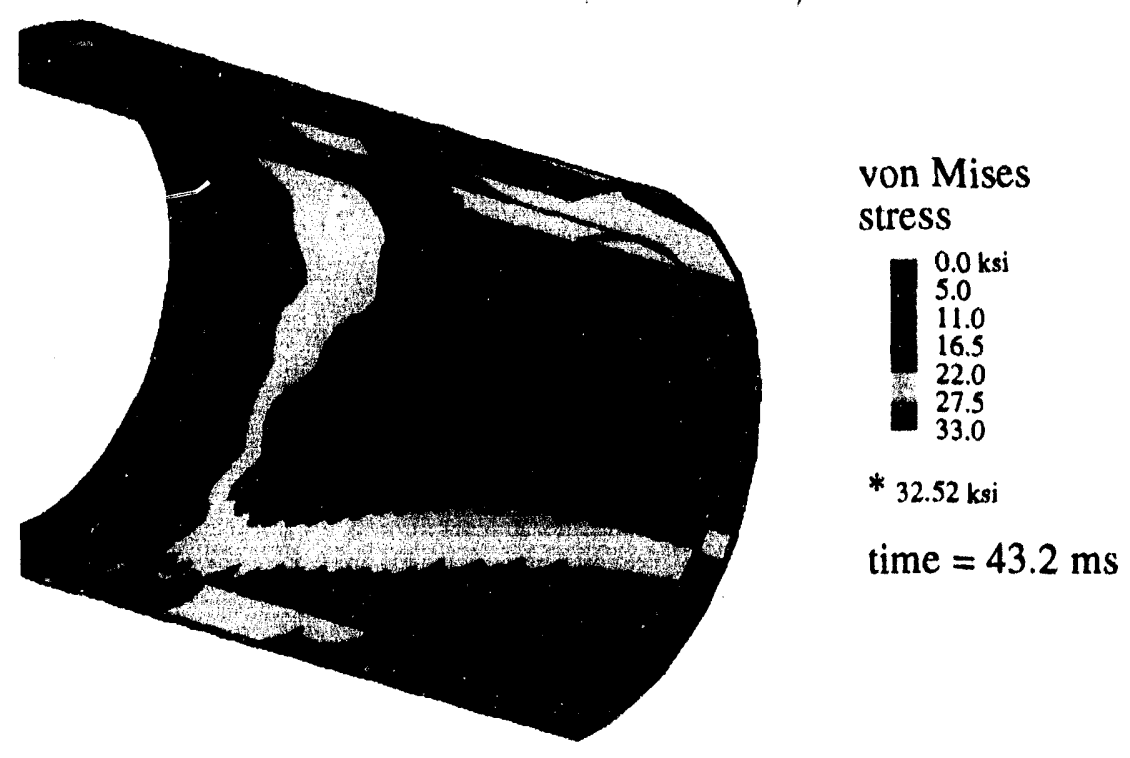

Figure 27. Maximum von Mises stress during the $30 \mathrm{ft}$. side drop of inelastic rail cask

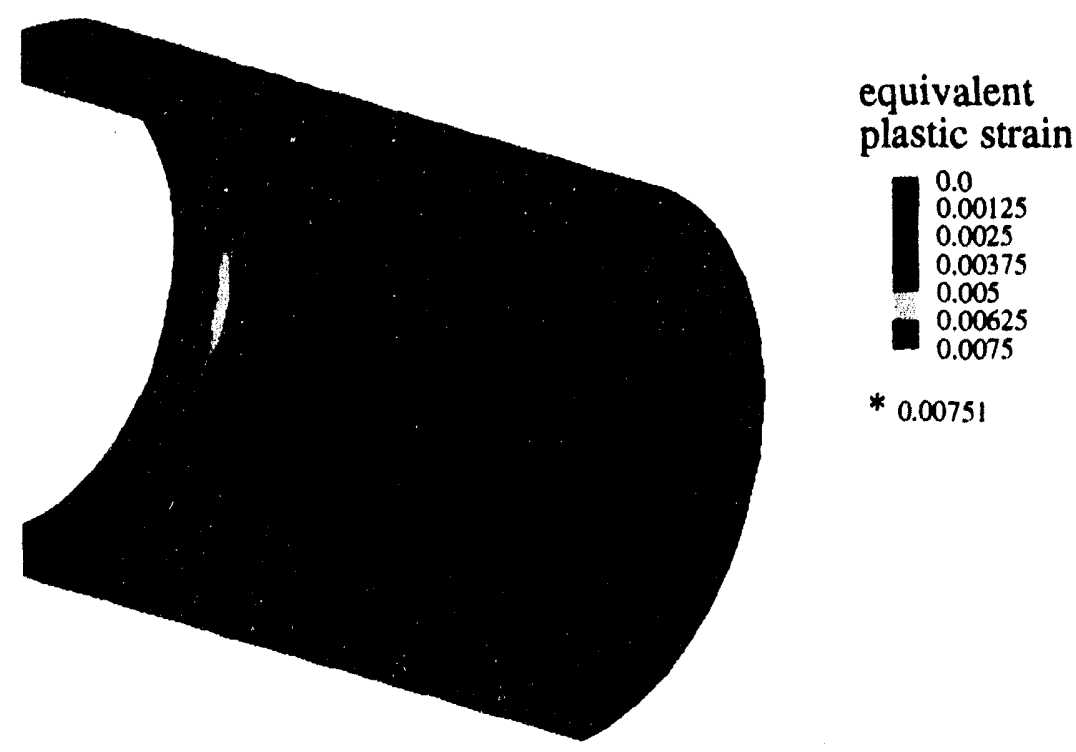

Figure 28. Equivalent plastic strain after 30 -foot side impact of rail cask 


\subsection{Comparison of elastic and inelastic design of rail cask}

Figure 29 and Figure 30 show the kinetic energy and g-loading histories during the side drop scenario for both the elastic and inelastic rail cask. Both the kinetic energy and g-loading are representative of the overall body's behavior during the impact event. While these results appear nearly identical, major differences still occur in the predicted stress histories of the two casks. Since the inner and outer shells are inelastic materials and deform significantly once yielding has occurred, the loading is redistributed to locations in the structure with less loading. This capability of redistributing stress greatly influenced further stress history. A further benefit of this stress redistribution is the more efficient use of the material.

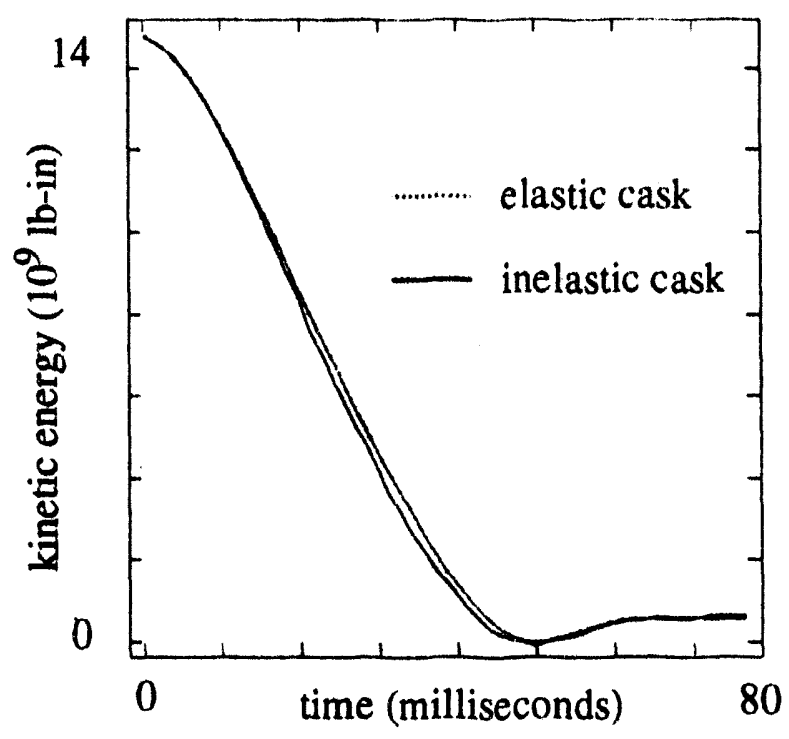

Figure 29. Kinetic energy history for elastic and inelastic rail cask

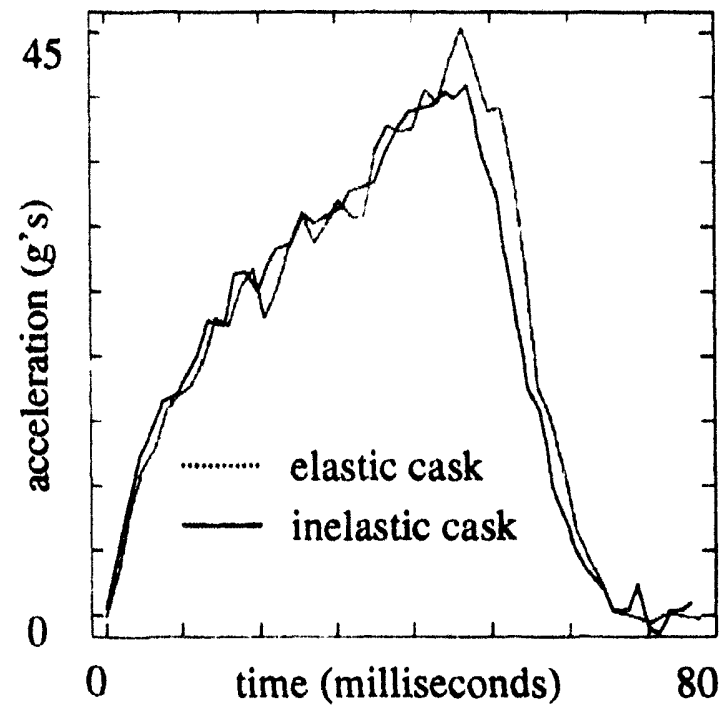

Figure 30. G-loading history for elastic and inelastic rail cask subjected to $30 \mathrm{ft}$. side drop 


\subsection{Elastic design of truck cask}

The $30 \mathrm{ft}$. side drop impact was modelled as a dynamic event with initial velocity of $\mathbf{5 2 7 . 4 5}$ in/s. Figure 31 shows the deformed shape of the iruck cask with elastic inner and outer stainless steel shells and elastic stainless steel end walls. Only the impact limiter appears to have noticeable amounts of deformation. The volumetric crushing of the polyurethane foam impact limiter is evenly distributed over a large footprint. The entire end drop event occurs over a time of approximately $\mathbf{4 0}$ milliseconds from initial cask impact to rebound.

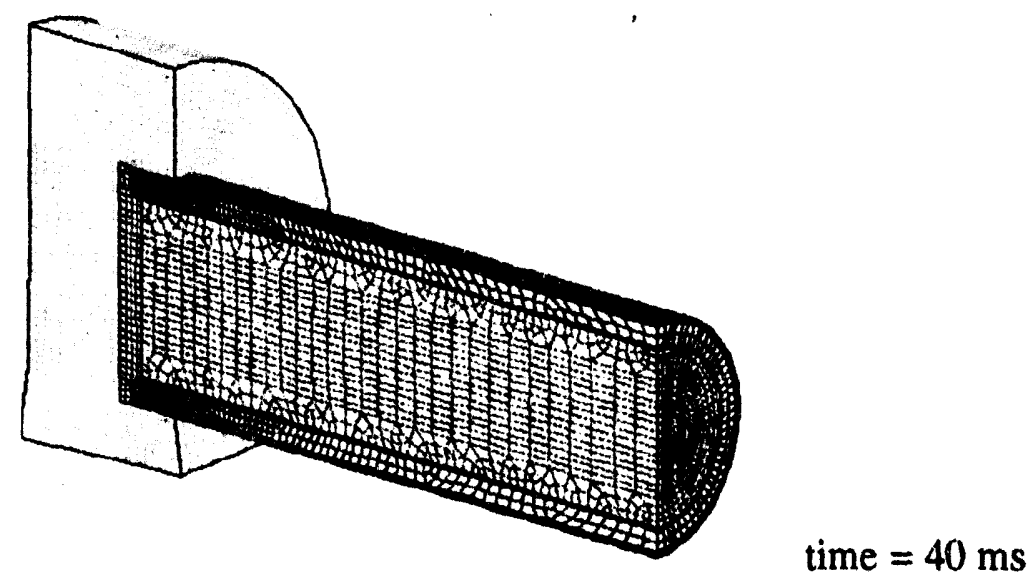

Figure 31. Deformed elastic truck cask after $30 \mathrm{ft}$. side drop

The maximum von Mises stress was $51.75 \mathrm{ksi}$ at 17.6 milliseconds which nearly corresponds to the maximum g-loading on the cask. The location of this maximum stress, denoted by the star, was in the outer shell as shown in Figure 32. This stress is the result of the overall bending of the truck cask. The maximum combined membrane and bending engineering stress of $51.84 \mathrm{ksi}$ is below the maximum allowable combined membrane and bending stress of $70 \mathrm{ksi}$. The truck cask is therefore acceptable based on the elastic design criterion for the side impact.
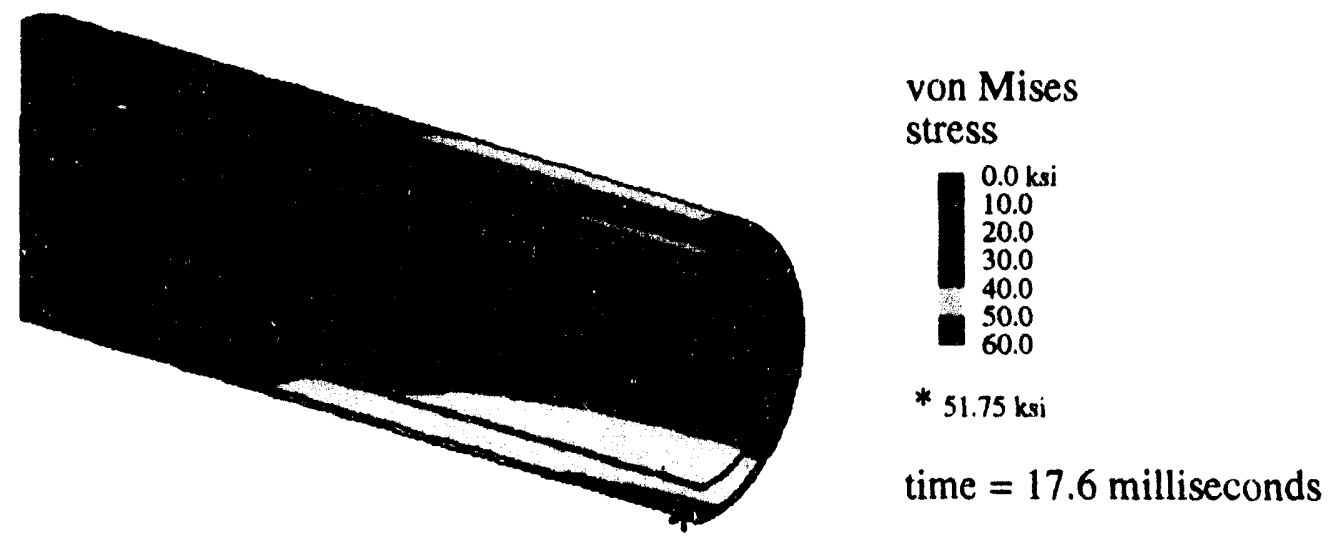

Figure 32. Maximum von Mises stress during the $30 \mathrm{ft}$. side drop of elastic truck cask 


\subsection{Inelastic design of truck cask}

Figure 33 shows the deformed shape of the inelastic rail cask subjected to a $30 \mathrm{ft}$. side drop impact with the same initial velocity of $527.45 \mathrm{in} / \mathrm{s}$. Again, the only noticeable deformation occurs in the impact limiter due to its volumetric crushing during impact.

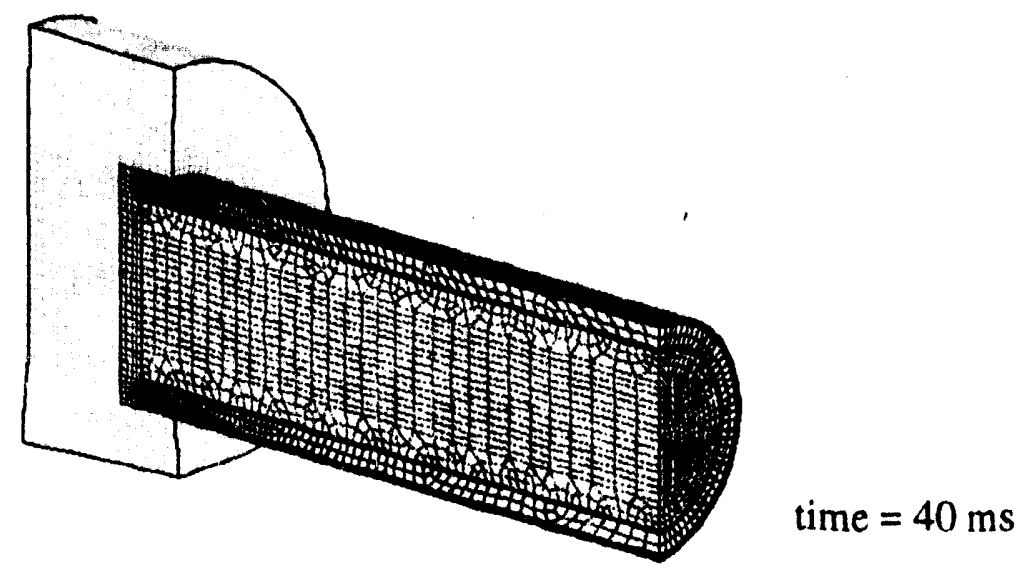

Figure 33. Deformed inelastic truck cask after $30 \mathrm{ft.side}$ drop

As was the case in the elastic design of the truck cask, a significant amount of bending deformation also occurs in the side drop of the inelastic truck cask. However, the slight amount of yielding in the inner and outer shell redistributes the resulting stress to surrounding locations in the shells and to the depleted uranium. During the impact (up until the occurrence of maximum g-loading at 25 milliseconds), the cask experiences a maximum von Mises stress of $31.14 \mathrm{ksi}$, as shown in Figure 34.
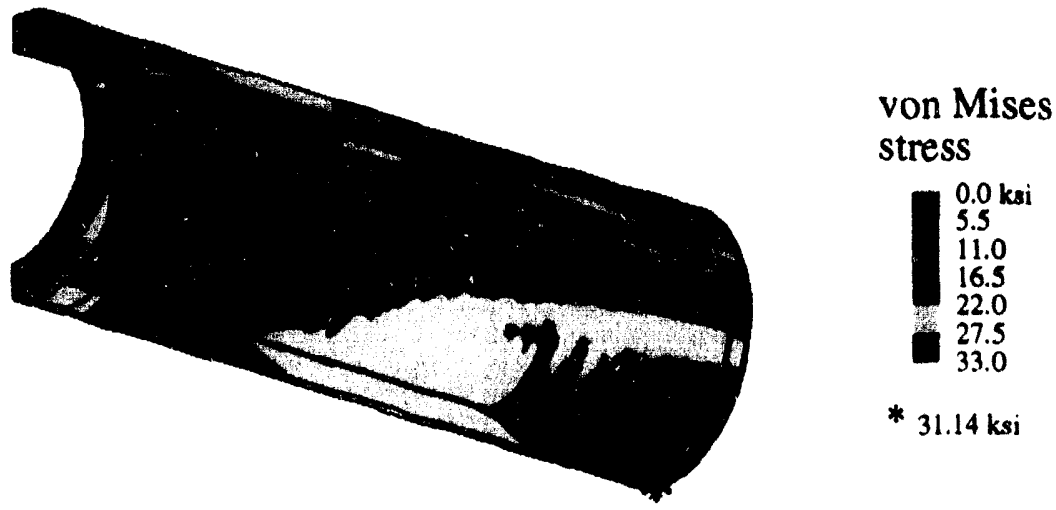

Figure 34. Von Mises stress in outer shell at $22.5 \mathrm{~ms}$.

Rebound of the cask results in a maximum von Mises stress of $36.53 \mathrm{ksi}$. The location of this maximum stress occurs at the top of the outer shell, as shown in Figure 35. Since the magnitude of the von Mises stresses in the inner and outer shells are not much beyond the elastic limit, the plastic strains are small. However, through-thickness plastic straining still occurs in the inner and outer shell of the truck cask, as shown in Figure 36. 

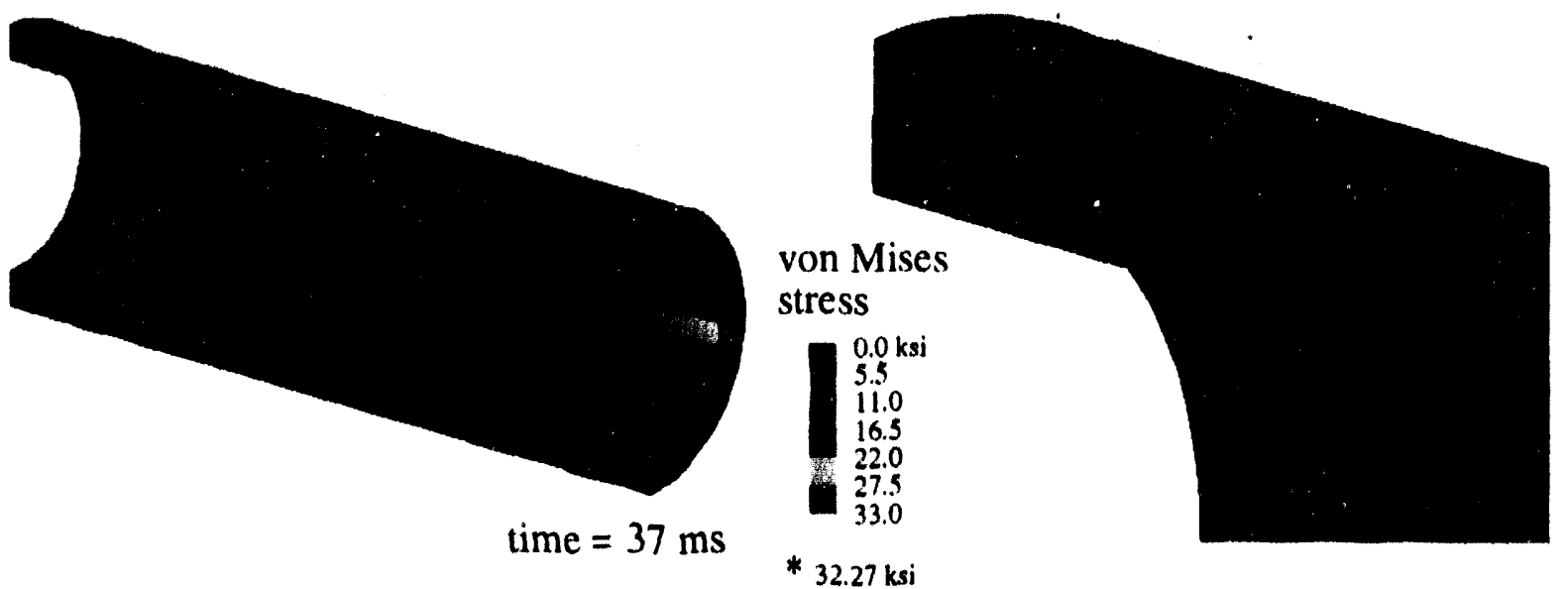

Figure 35. Maximum von Mises stress during the $30 \mathrm{ft}$. side drop of inelastic truck cask

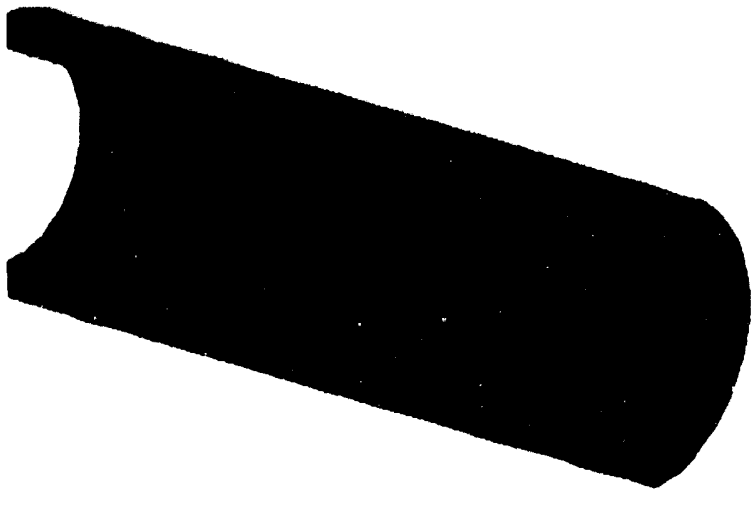

equivalent plastic strain

$* 0.0064$

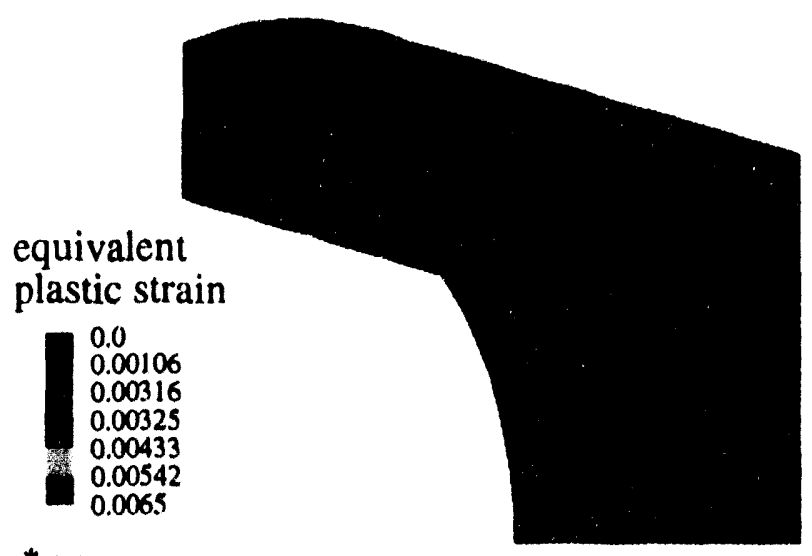

Figure 36. Equivalent plastic strain after 30-foot side drop of truck cask

\subsection{Comparison of elastic and inelastic design of truck cask}

Figure 37 and Figure 38 show the kinetic energy and g-loading histories during the side drop scenario for both the elastic and inelastic rail cask. Both the kinetic energy and g-loading are representative of the body's overall behavior during the impact event. While these results appear nearly identical, differences occur in the predicted location and time of the maximum stress in the two casks. The difference between the maximum predicted von Mises stress of the elastic analysis and inelastic analysis is significant. The inelastic cask is capable of yielding and redistributing its load to other parts of the structure, which effectively changes the loading history within the cask. This change of loading history cannot be predicted without inelastic analysis. 


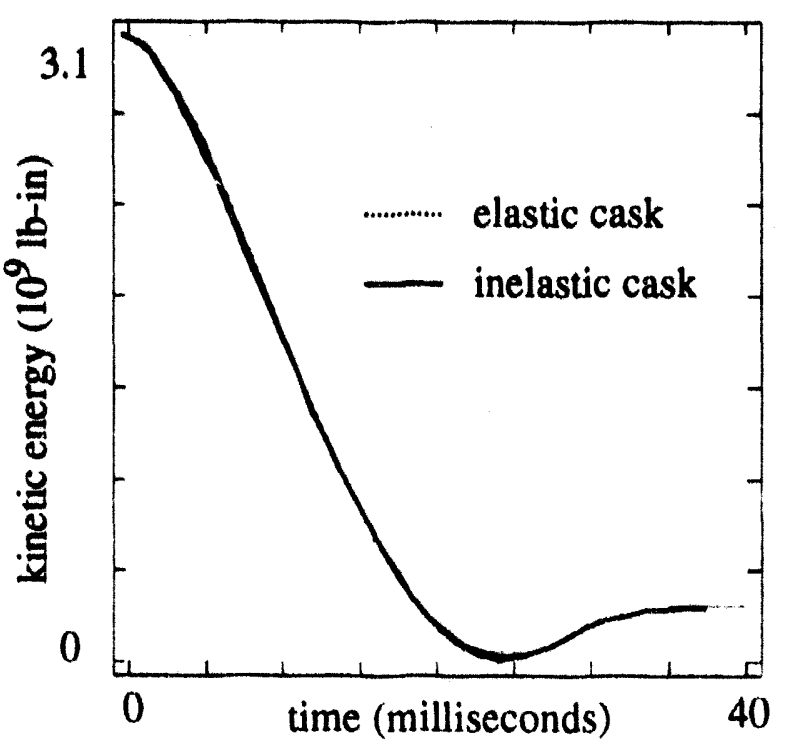

Figure 37. Kinetic energy history for elastic and inelastic truck cask subjected to $30 \mathrm{ft}$ side drop

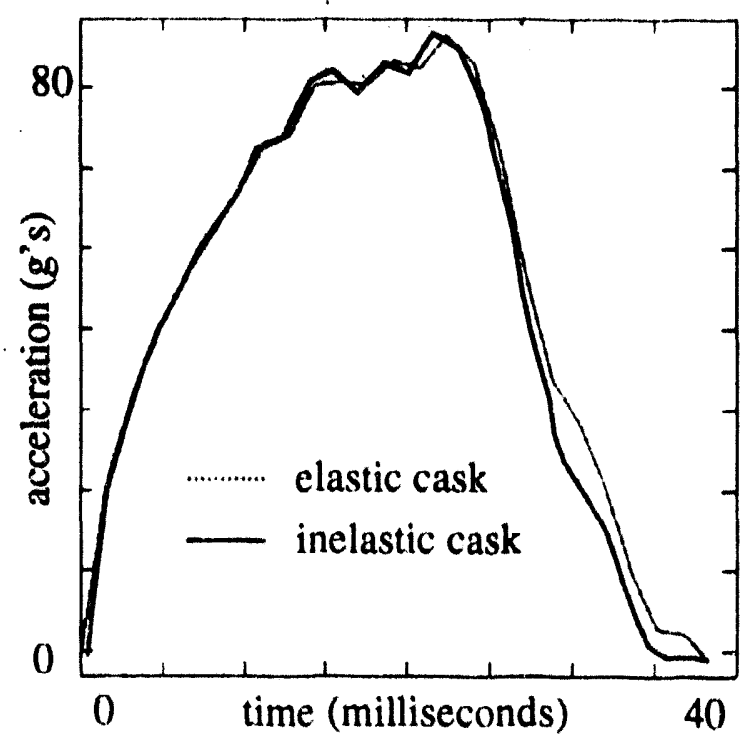

Figure 38. G-loading history for elastic and inelastic truck cask subjected to $30 \mathrm{ft}$. side drop 


\section{CG-Over Corner Impact}

\subsection{Finite element model}

The finite element models for the rail and truck RAM transportation package $30 \mathrm{ft}$. corner drop scenarios are shown in Figure 39. Only a half of the entire cask was modelled due to symmetry. PRONTO3D was again used in all of the analyses.

The components were modelled separately so that the gamma shielding was allowed to slide within the inner and outer 304 stainless steel shells. Likewise the contents were allowed to push and freely slide against the inner shell. As was the case with the side drop analyses, only a full cask was considered. Again, this is due to the observation that the orientation of the impact event has a role in the interaction between the cask and the contents. For the center-ofgravity-over-corner impact event difference between a full or nearly full cask would be negligible. The cask end wall was modelled separately and was fixed against the side wall. The impact limiters were also fixed against the end and side walls.

The rail cask was modelled with a total of 31960 elements with two elements through the thickness of the inner shell and two elements through the thickness of the outer shell. Likewise, the truck cask was modelled with a total of 32344 elements with two elements through the thickness of the inner shell and outer shell. This was due to the large amounts of CPU time that would have been required for more than two elements through the thickness of the shells. The qualitative nature of the comparisons presented here should not change even if more elements were used.

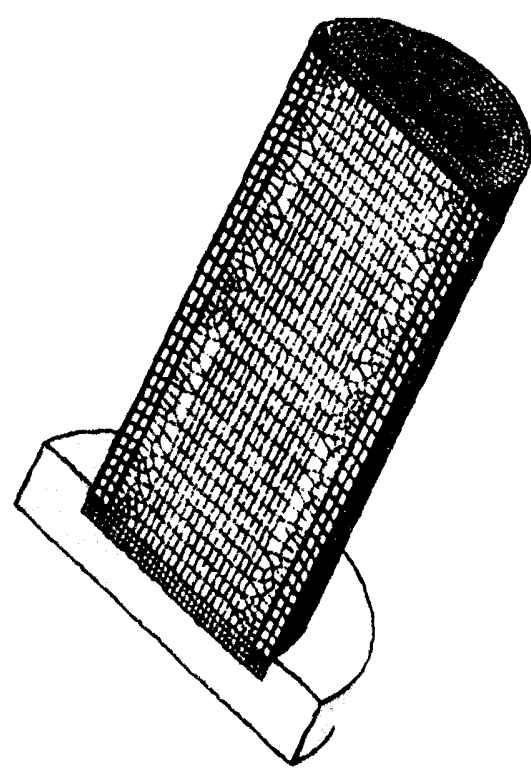

rail cask

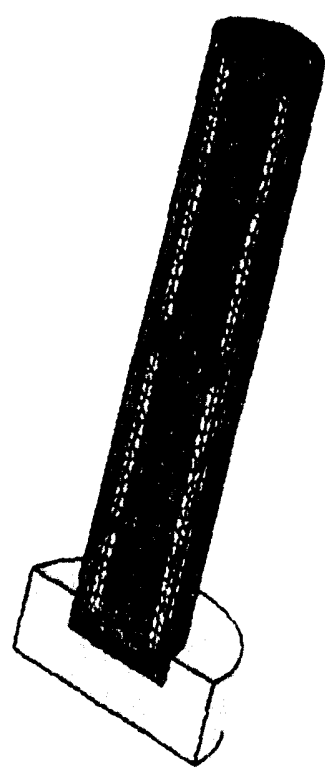

truck cask

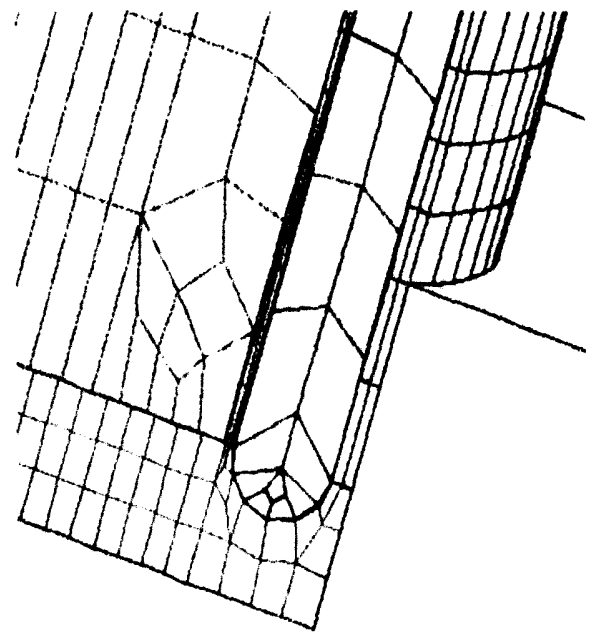

corner detail

Figure 39. Finite element models for the rail and truck RAM transportation package $30 \mathrm{ft}$. corner drop scenario 


\subsection{Elastic design of rail cask}

The impact was modelled as a dynamic event with initial velocity of $527.45 \mathrm{in} / \mathrm{s}$ corresponding to a $30 \mathrm{ft}$. drop. Figure 40 shows the deformed shape of the rail cask with elastic inner and outer stainless steel shells and elastic stainless steel end walls. A considerable amount of local deformation and volumetric crushing occurs in the impact limiter near the corner of the cask. Otherwise, there is no visible deformation in the cask. The entire corner drop event occurs over a time of approximately 80 milliseconds.

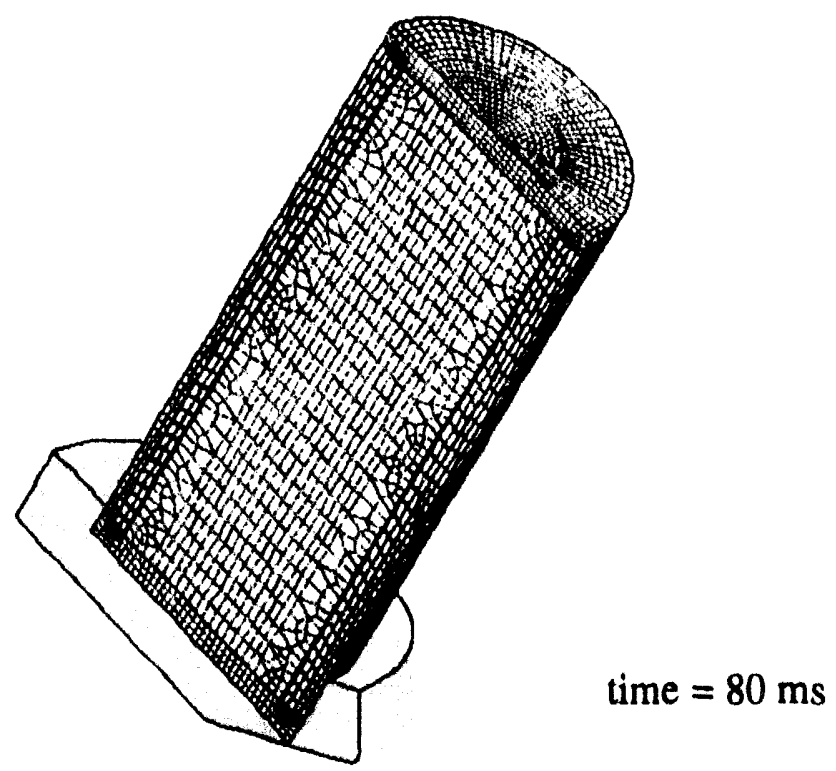

Figure 40. Deformed elastic rail cask after $30 \mathrm{ft}$. corner drop

Figure 41 shows a series of von Mises stress contours plotted at $40 \mathrm{msec}, 48 \mathrm{msec}$, and 56 msec for the elastic analysis. The displacements are shown magnified by $5 x$. The outer shell thickness was $0.6 \mathrm{in}$. The stresses clearly exceed the allowable stress, and the cask needs to be redesigned to meet the design criterion. The high stresses are due to a combination of the endwall bending the shell and the inward pressure of the impact limiter on the outer shell. Note that the original outer shell thickness of $0.6 \mathrm{in}$. is the same used in the inelastic analysis. The outer shell thickness was significantly increased to 3.5 in. during redesign, yet the maximum stress from the elastic analysis still exceeded the allowable stress. With the outer shell thickness of 3.5 inches the maximum von Mises stress was $86.8 \mathrm{ksi}$ at 59.2 milliseconds which corresponds to the maximum g-loading on the cask. The location of this maximum stress, denoted by the star, was in the outer shell as shown in Figure 42 . Because of the relatively small stiffness of the lead shielding, practically none of the load on the outer shell is transferred to the inner shell. The maximum von Mises stress of $86.8 \mathrm{ksi}$ for an outer shell thickness of 3.5 inches exceeds the maximum allowable stress specified by the NRC Regulatory Guide 7.6. Further increases in the outer shell thickness were deemed no longer realistic and therefore no further redesign was attempted. 


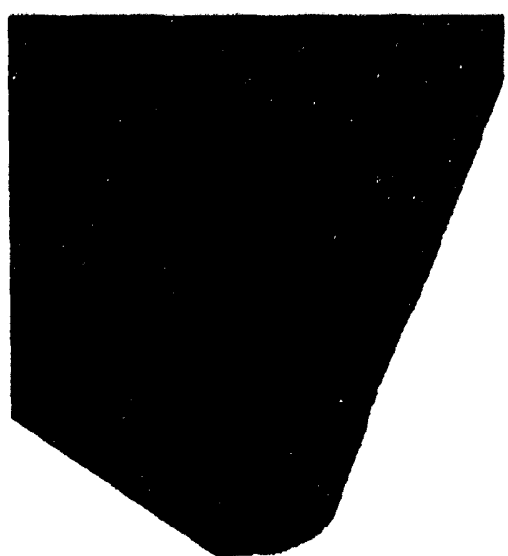

time $=40$ milliseconds $*=70.27 \mathrm{ksi}$ von Mises

stress

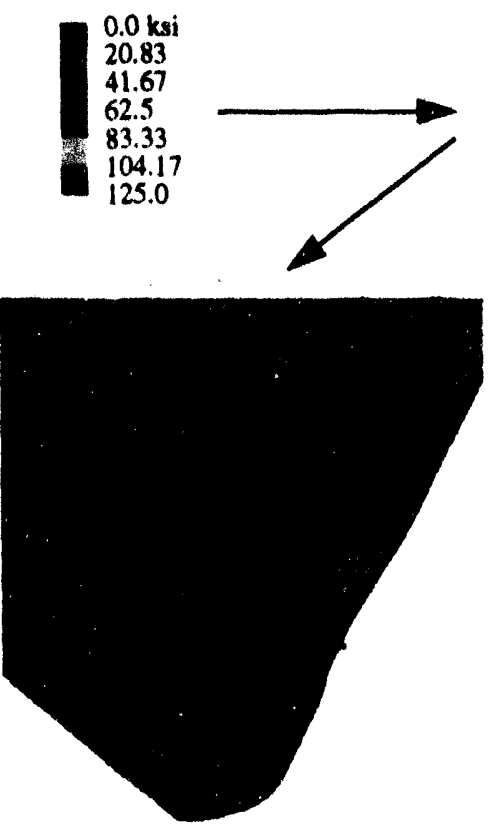

time $=56$ milliseconds

$*=83.3 \mathrm{ksi}$

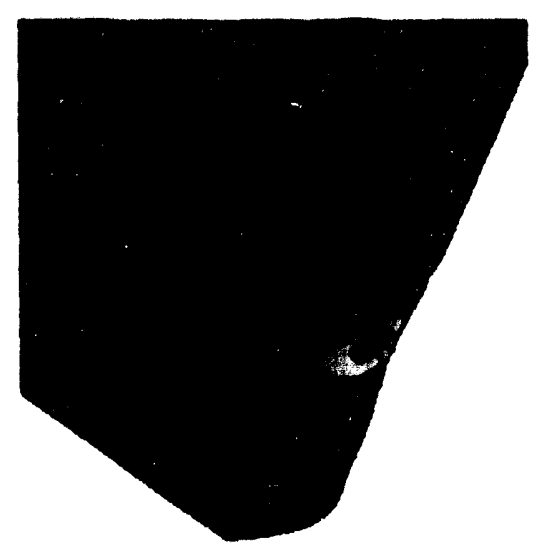

time $=48$ milliseconds $*=123.5 \mathrm{ksi}$

Figure 41. Von Mises stress history in the outer shell (for 0.6 in. thickness) of the elastic rail cask. Displacements are magnified by $5 x$.

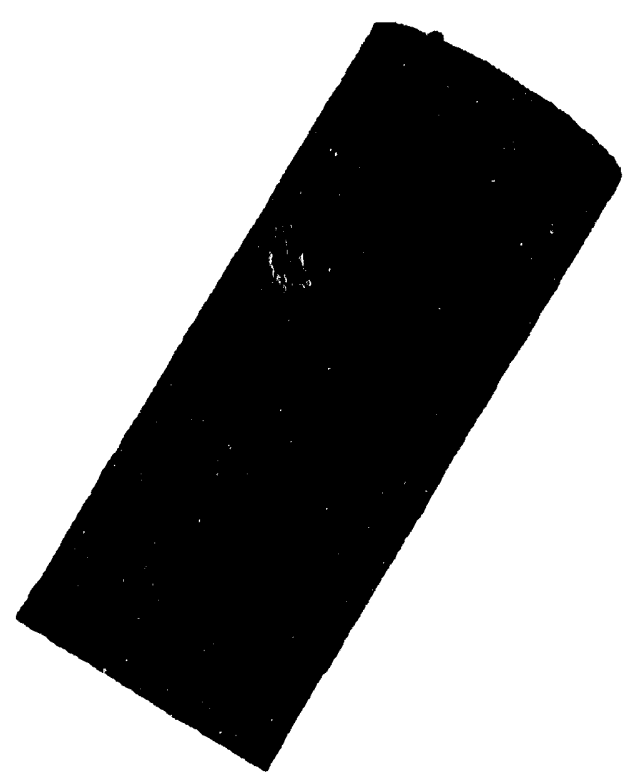

Figure 42. Maximum von Mises stress during the $30 \mathrm{ft}$. corner drop of elastic rail cask (for 3.5 in. outer shell thickness) 


\subsection{Inelastic design of rail cask}

Figure 43 shows the deformed shape of the inelastic rail cask subjected to a $30 \mathrm{ft}$. corner drop with the same initial velocity of $527.45 \mathrm{in} / \mathrm{s}$. It appears that the only noticeable deformation occurs in the impact limiter as it volumetrically crushes near the comer of the cask during impact.

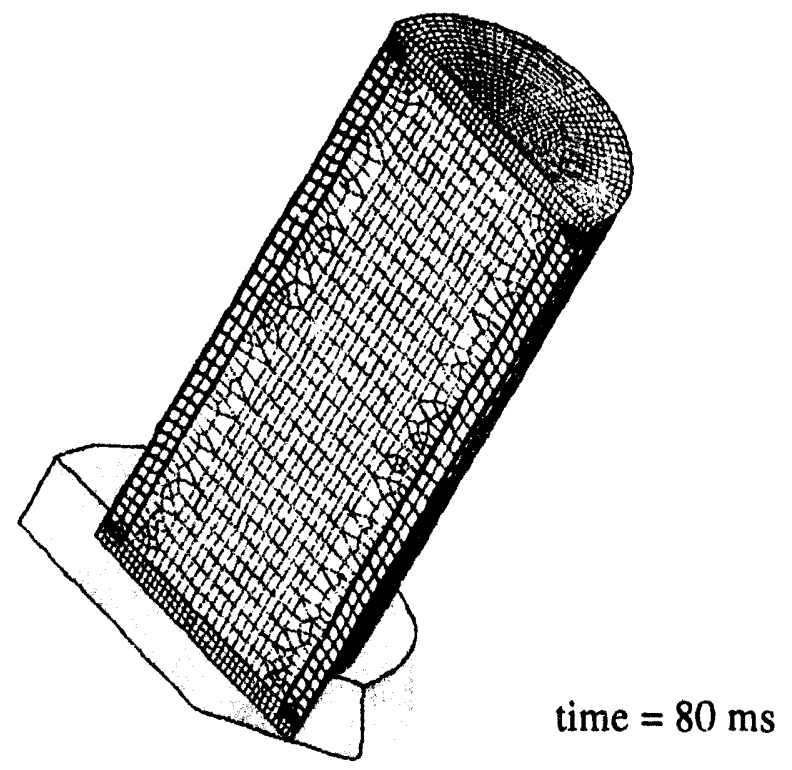

Figure 43. Deformed inelastic rail cask after $30 \mathrm{ft} . c o r n e r$ drop
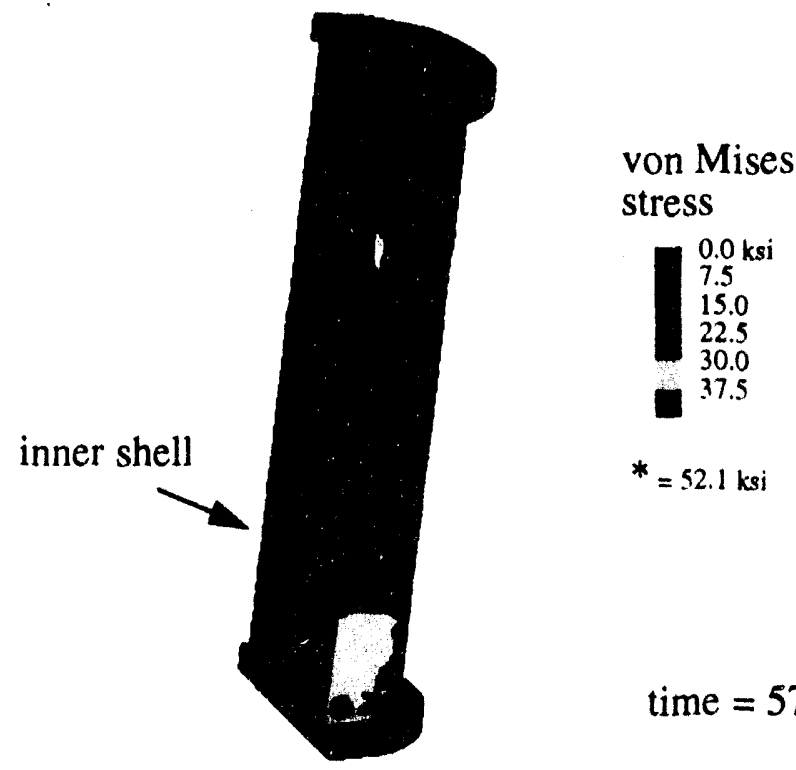

von Mises

stress

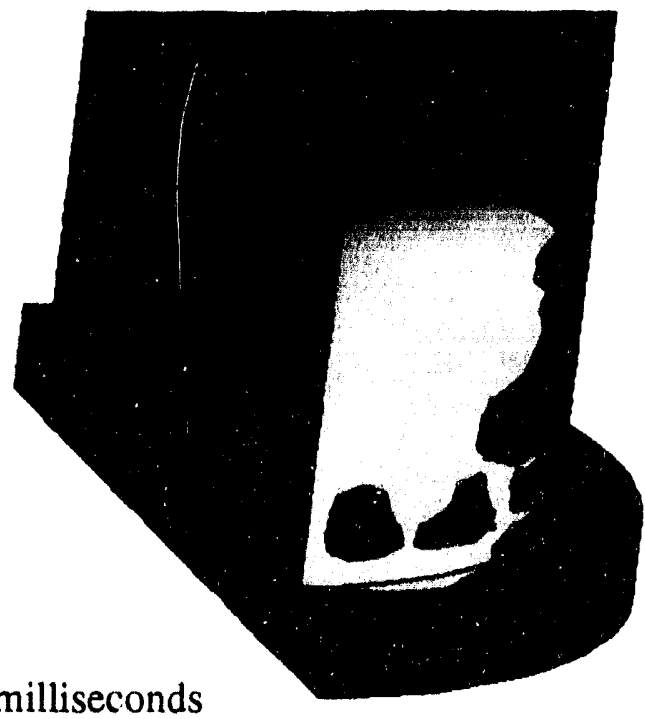

Figure 44. Maximum von Mises stress during the $30 \mathrm{ft}$. corner drop of inelastic rail cask

In the inelastic analysis for an uuter shell thickness of 0.6 in., the von Mises stress also increases in the outer shell as the cask is loaded to the maximum g-load. Because the stainless steel shell is allowed to yield, part of the load is transferred to the shielding and inner wall. 
The maximum von Mises stress during the corner drop event, was $52.1 \mathrm{ksi}$ at 57.2 milliseconds. The location of this maximum stress, as shown in Figure 44, was in the inner shell. For the inelastic analysis, a plastic strain of 0.063 for the 304 stainless steel was observed in the inner shell of the cask, as shown in Figure 45. This plastic strain is a result of the deformation caused by the load transferred from the outer shell to the shielding and then to the inner shell. This load redistribution behavior is predicted by the inelastic analysis only.

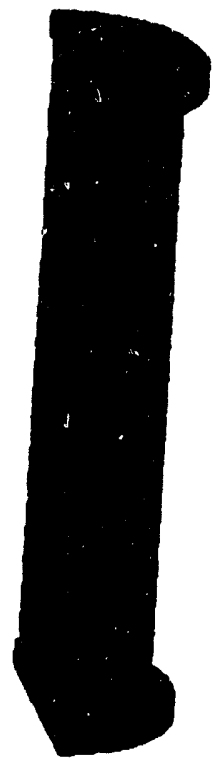

equivalent plastic strain

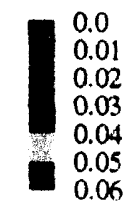

$*=0.063$

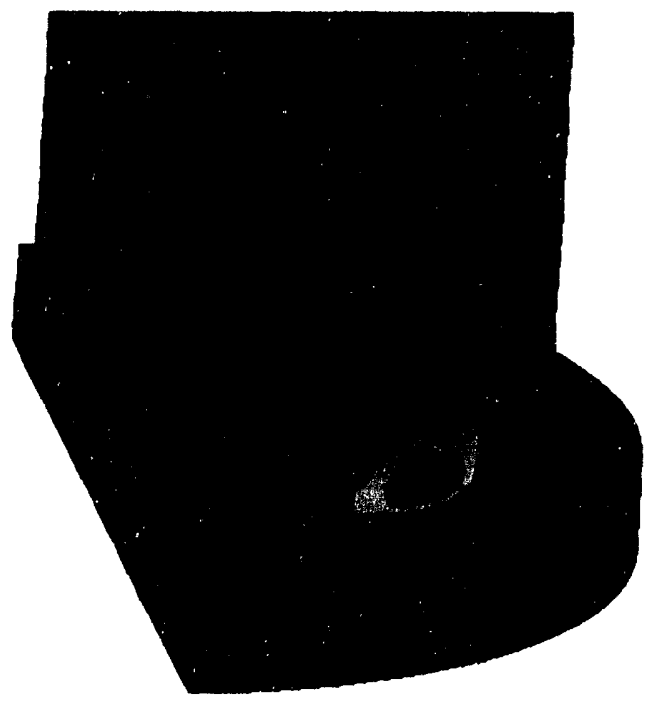

Figure 45. Equivalent plastic strain after 30 -foot corner drop of rail cask

\subsection{Comparison of elastic and inelastic design of rail cask}

Figure 46 and Figure 47 show the kinetic energy and g-loading histories during the corner drop scenario for both the elastic and inelastic rail cask. Both the kinetic energy and g-loading are representative of the body's overall behavior during the impact event. The kinetic energy and g-loading histories are considerably different for the elastic and inelastic analyses. The kinetic energy does not drop to zero as in the case of the end and side drop scenarios. Instead some of the initial translational kinetic energy is converted to rotational kinetic energy. For the elastic analysis the kinetic energy drops from approximately $64 \times 10^{9} \mathrm{lb}$-in. $\left(32 \times 10^{9} \mathrm{lb}\right.$-in. for half of the cask) down to $18 \times 10^{9} \mathrm{lb}$-in. ( $9 \times 10^{9} \mathrm{lb}$-in. for half of the cask) over a time of 50 milliseconds and then increases as the elastic outer shell unloads and the cask begins to rotate. For the inelastic analysis, the kinetic energy drops from approximately $60 \times 10^{9} \mathrm{lb}$-in. $\left(30 \times 10^{9} \mathrm{lb}\right.$-in. for half of the cask) down to $7 \times 10^{9} \mathrm{lb}$-in. $\left(3.5 \times 10^{9} \mathrm{lb}\right.$-in. for half of the cask) over a time of 58 milliseconds. The small difference between the initial kinetic energies of the two casks is due to the increased mass from the large 3.5 inch outer shell thickness used in the elastic analysis. The g-loading was approximately $60 \mathrm{~g}$ in the elastic analysis and $40 \mathrm{~g}$ in the inelastic analysis. The difference in the g-loading for the elastic and inelastic analyses is due to the fact that the stiffness of the cask with elastic inner and outer shells is considerably higher than that for the inelastic shells. In addition to the inelastic shells deforming plastically, the lead shielding also plastically deforms, and together they absorb a considerable amount of energy and reduce 
the severity of the impact. This is not the case for the elastic cask.

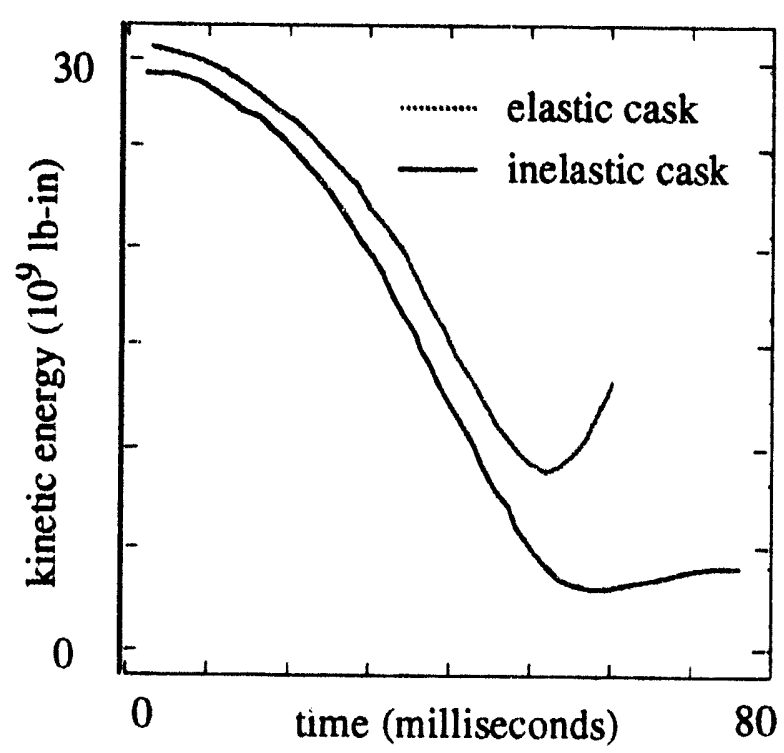

Figure 46. Kinetic energy history for elastic and inelastic rail cask subjected to $30 \mathrm{ft}$ corner drop

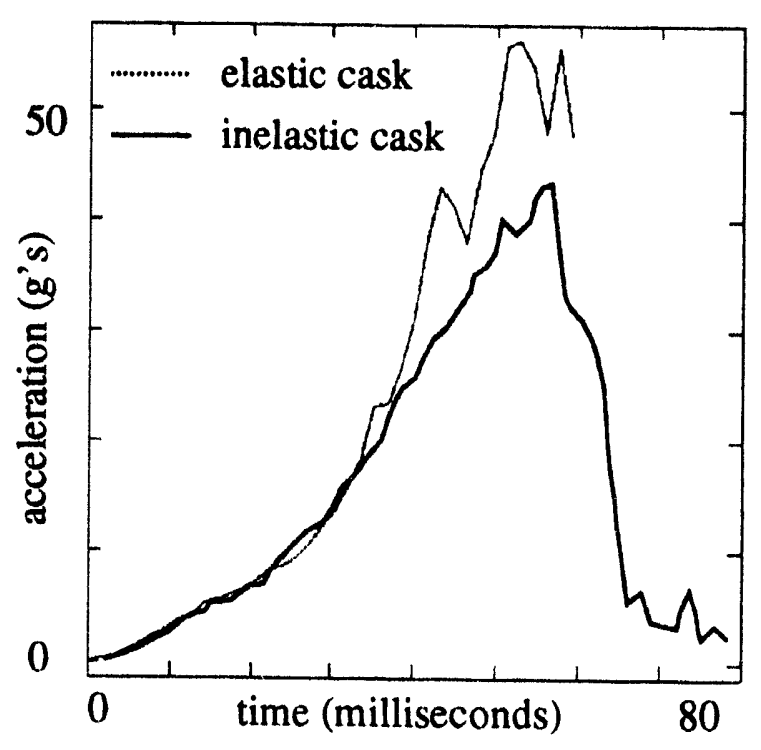

Figure 47. G-loading history for elastic and inelastic rail cask subjected to $30 \mathrm{ft}$. corner drop

\subsection{Elastic design of truck cask}

The impact was modelled as a dynamic event with initial velocity of $527.45 \mathrm{in} / \mathrm{s}$ corresponding to a $30 \mathrm{ft}$. corner drop. Figure 48 shows the deformed shape of the truck cask with elastic inner and outer stainless steel shells and elastic stainless steel end walls. Only a slight amount of volumetric crushing occurs in the impact limiter. The entire corner drop event occurs over a time of approximately $\mathbf{5 0}$ milliseconds from initial impact to rebound.

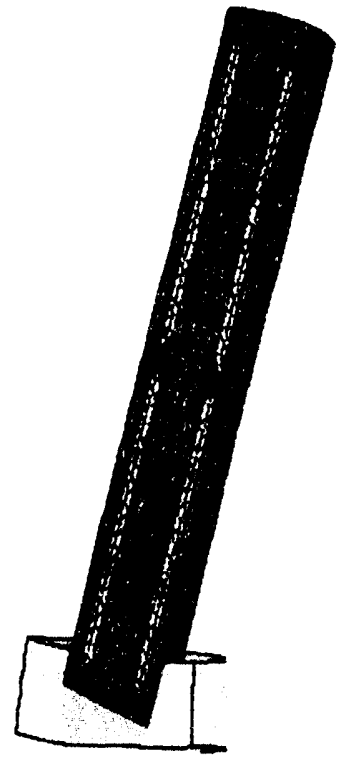

time $=50 \mathrm{~ms}$

Figure 48. Deformed elastic truck cask after $30 \mathrm{ft}$. corner drop 
The maximum von Mises stress was $151.9 \mathrm{ksi}$ at 9.05 milliseconds which corresponds to the maximum g-loading on the cask. The location of this maximum stress, denoted by the star, was in the outer shell as shown in Figure 49. This level of stress (an engineering stress of 152 $\mathrm{ksi}$ ) is well beyond the allowable stress of $70 \mathrm{ksi}$; however, no redesign was attempted. Based on the elastic analysis of the rail cask cg-over-comer impact, it is expected that the redesign of the truck cask would require a significant increase in shell thickness.
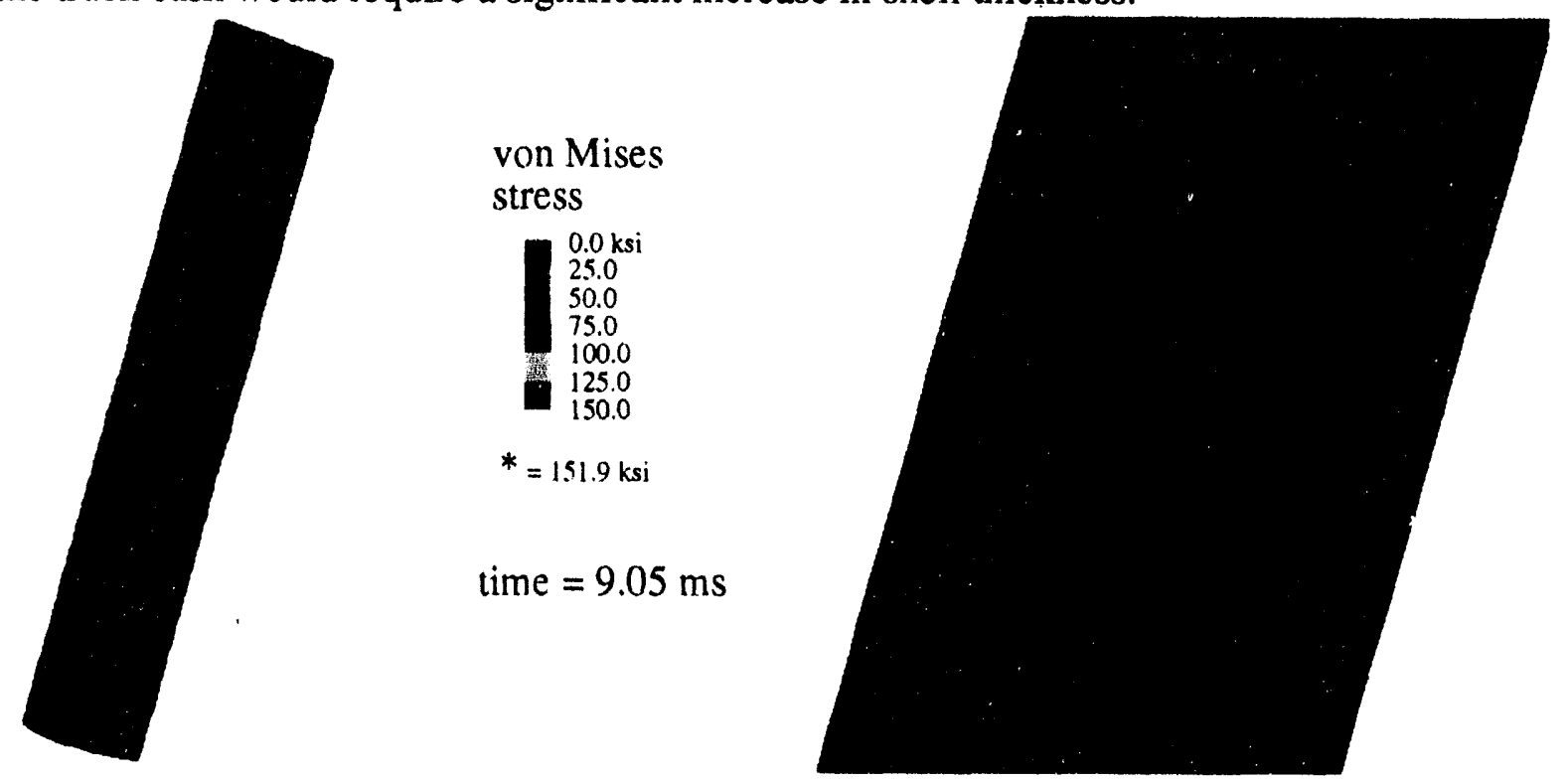

Figure 49. Maximum von Mises stress during the $30 \mathrm{ft}$. corner drop of elastic truck cask

\subsection{Inelastic design of truck cask}

Figure 50 shows the deformed shape of the inelastic truck cask subjected to a $30 \mathrm{ft}$. corner drop with initial velocity of $527.45 \mathrm{in} / \mathrm{s}$. Only a slight amount of volumetric crushing occurs in the impact limiter. Otherwise, there is no visible deformation in the cask.

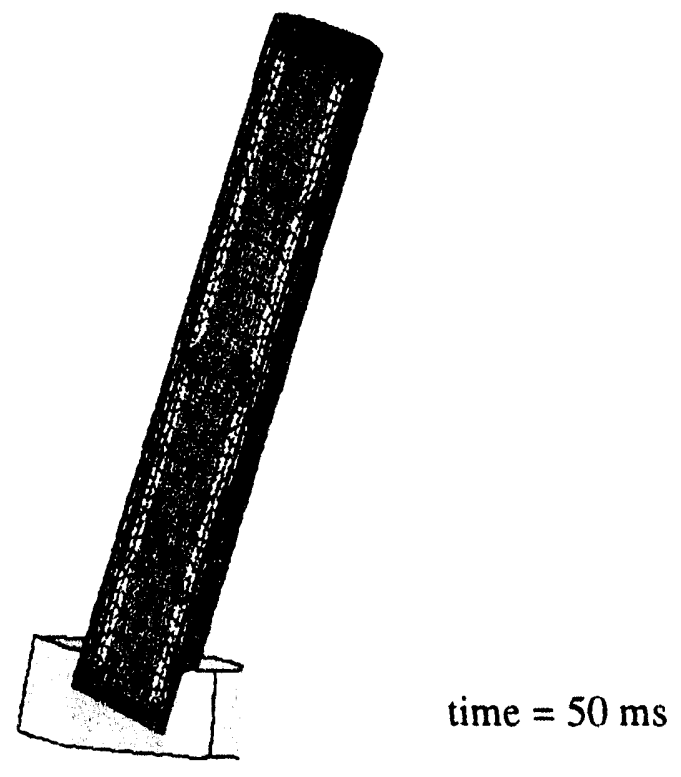

Figure 50. Deformed inelastic truck cask after $30 \mathrm{ft}$. corner drop 
In the inelastic analysis, the maximum von Mises stress of $41.8 \mathrm{ksi}$ also occurs in the outer shell of the truck cask as shown in Figure 51. It occurs at 17.6 milliseconds and is also due to an instability in the outer shell. The slight amount of yielding and plastic straining (shown in Figure 52) in the outer shell redistributes this stress to the depleted uranium.

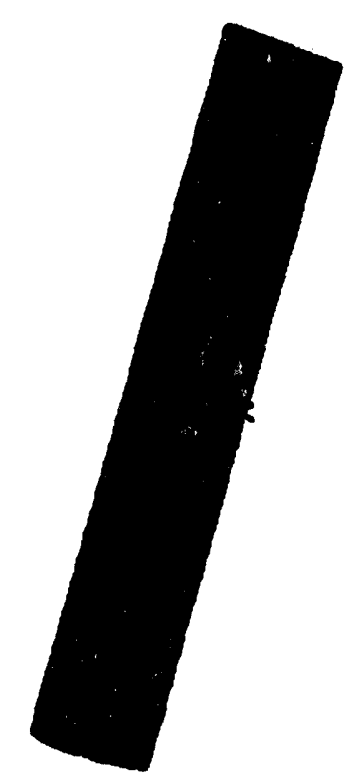

von Mises

stress

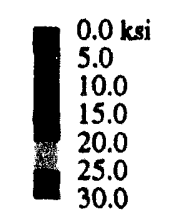

$*=41.8 \mathrm{ksi}$

time $=17.6 \mathrm{~ms}$

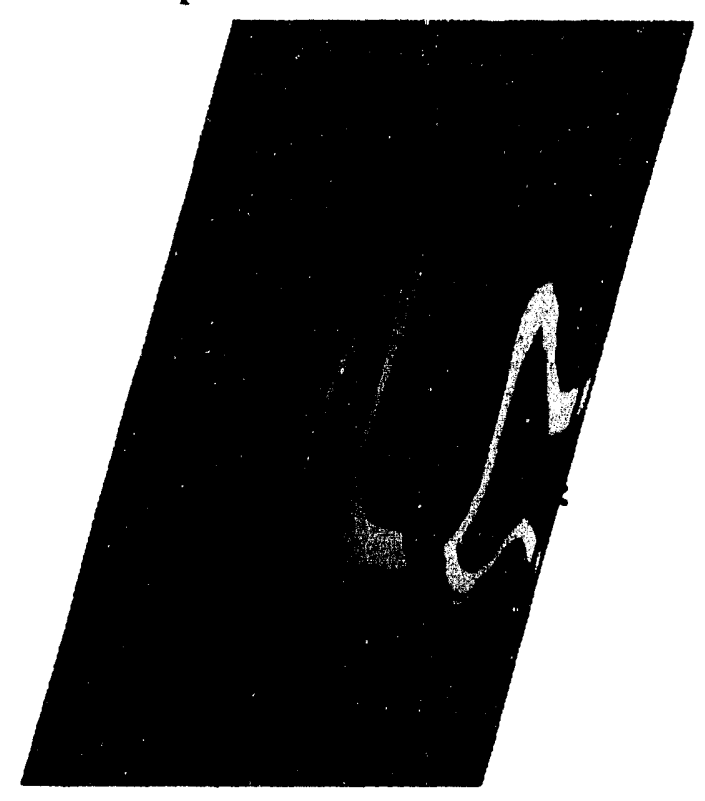

Figure 51. Maximum von Mises stress during the $30 \mathrm{ft}$. corner drop of inelastic truck cask

Since the magnitude of the von Mises stresses in the inner and outer shells are not much beyond the elastic limit, the plastic strains are small. However, through-thickness plastic straining still occurs in the outer shell of the truck cask.

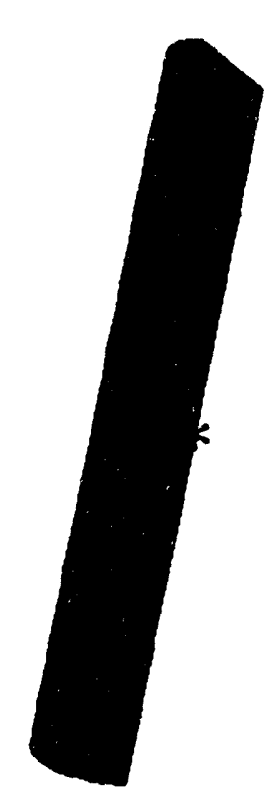

$$
\begin{aligned}
& \text { equivalent } \\
& \text { plastic strain } \\
& \begin{array}{l}
0.0 \\
0.006 \\
0.011 \\
0.017 \\
0.023 \\
0.028 \\
0.034
\end{array} \\
& *=0.0337
\end{aligned}
$$

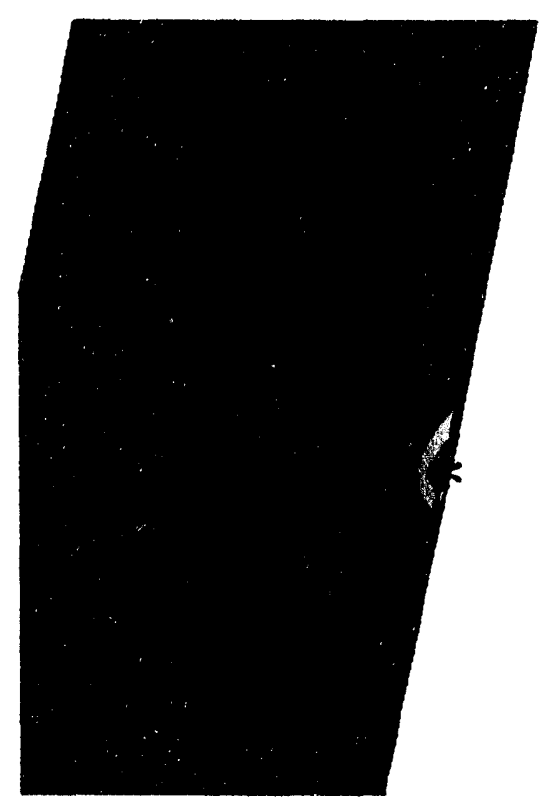

Figure 52. Equivalent plastic strain after 30 -foot corner drop of truck cask 


\subsection{Comparison of elastic and inelastic design of truck cask}

Figure 53 and Figure 54 show the kinetic energy and g-loading histories during the corner drop scenario for both the elastic and inelastic truck cask. Both the kinetic energy and g-loading are representative of the body's overall behavior during the impact event. The kinetic energy and g-loading histories are nearly identical for the elastic and inelastic analyses. The kinetic energy drops from approximately $16 \times 10^{9} \mathrm{lb}$-in. $\left(8 \times 10^{9} \mathrm{lb}\right.$-in. for half of the $\left.\mathrm{cr} \cdot \mathrm{k}\right)$ down to $1.6 \times 10^{9} \mathrm{lb}$-in. $\left(0.8 \times 10^{9} \mathrm{lb}\right.$-in. for half of the cask) over a time of 37 milliseconds and then increases. The g-loading was approximately $35 \mathrm{~g}$ in both cases, as shown in Figure 54 .

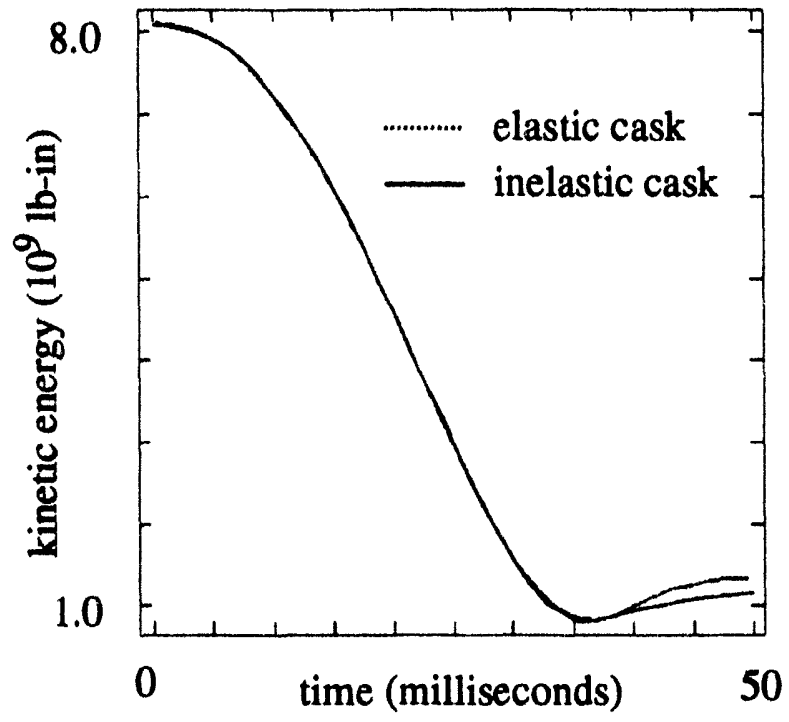

Figure 53. Kinetic energy history for elastic and inelastic truck cask subjected to $30 \mathrm{ft}$ corner drop

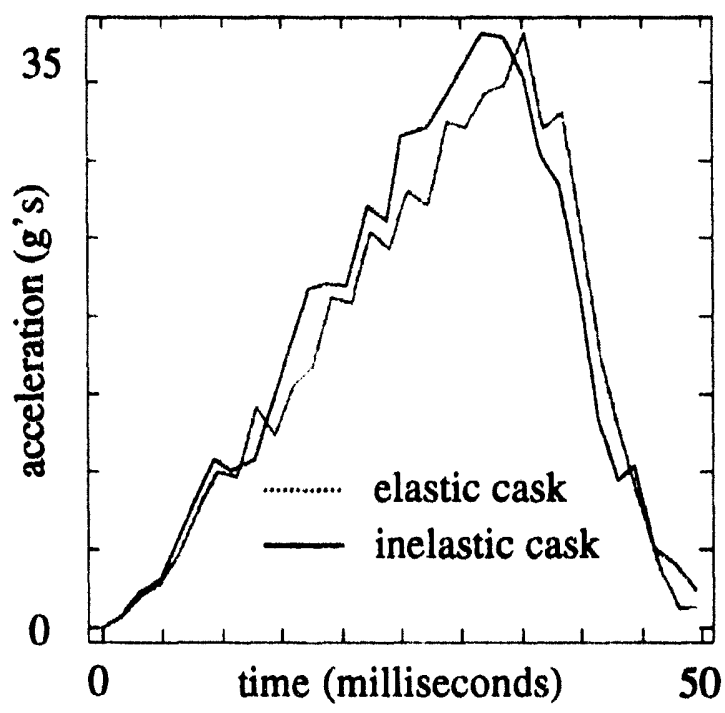

Figure 54. G-loading history for elastic and inelastic truck cask subjected to $30 \mathrm{ft}$. corner drop 


\section{Comparison of Results}

The impact scenarios in this study were modelled with a transient dynamic analysis technique and provided a foundation for comparing elastic and inelastic design methodologies. In the elastic analyses, nonlinear behavior was used for all materials except the stainless steel. In the inelastic analyses, nonlinear behavior was used for all materials including the stainless steel. The impact event is thus modelled in the most accurate way possible while retaining the requirement for elastic behavior of the stainless steel. It is more common for elastic analyses to be performed in an equivalent quasistatic fashion ignoring all sources of nonlinear behavior such as shielding response. This common analysis technique was not used in this study so that the comparisons would be based entirely on differences in the stainless steel shell response instead of difference in quasistatic and dynamic responses. A few issues have not been resolved and require further study. However, even with these limitations, the use of inelastic analysis for radioactive material transportation container design has a significant advantage over elastic analysis. Based on the impact scenarios of the rail and truck RAM packages studied, an improved knowledge of the behavior of the casks is obtained by using the inelastic analysis. This can lead to a better overall design as discussed below.

First, elastic analysis may underpredict maximum stress at a particular location, resulting in inappropriately sized wall sections. Elastic analysis does not properly account for the decrease in stiffness resulting from yielding in part of the structure and does not show the redistribution of load caused by this yielding. For the rail cask subjected to the center-of-gravity-over-corner impact, the elastic analysis underpredicted the stress in the inner shell. This was a result of the outer shell yielding and redistributing the load to the gamma shielding and inner shell. It was also observed in the inelastic analysis that significant plastic straining can occur through the thickness in several areas. This may indicate that the elastic analysis is neglecting significant physical features of the impact scenario.

Second, elastic analysis may overpredict the maximum stress. The inelastic shells can yield and redistribute the loading to other less loaded parts of the structure, whereas the elastic shells cannot predict this behavior. This was shown in both the side drop and center-of-gravity-overcorner drop analyses. For the rail cask subjected to the center-of-gravity-over-corner impact, the elastic analysis of the impact event would require an outer shell thickness of over 3.5 inches to meet the design criterion. With the same impact limiter, the inelastic analysis suggested that the loading on the outer shell causes it to yield and redistribute the load to the gamma shielding and inner shell. An outer shell thickness of only 0.6 inches is required. Therefore, the inelastic analysis may also allow for a better distribution of structural material, which can lead to weight savings. The weight savings can increase the capacity of the package, thereby decreasing the number of shipments required to transport a given quantity of material, which increases the overall shipping program safety. The use of inelastic analysis may also decrease the overall cost of a transportation package, especially for designs where multiple packages will be constructed. 


\section{Issues Involved in Conducting Accurate Analyses}

The use of transient dynamic inelastic analysis for RAM transportation containers potentially has several advantages over the currently used quasistatic elastic analysis. The most prominent of these is that the behavior of the package is captured more accurately. This leads to a better understanding of the response of the container to the loads applied to it. The transient dynamic analysis technique utilized in this study provides improved knowledge of the structural integrity of the cask. The traditional quasistatic elastic analysis relies on numerous assumptions whose effect on the package design and overall safety are not completely understood. In contrast, transient dynamic inelastic analysis can easily model many nonlinearities.

The transient dynamic analysis technique can more accurately predict the loading history of the cask by modelling all sources of nonlinearity. That includes the nonlinear thermo-mechanical behavior of the cask materials, i.e. shielding, contents, and impact limiters, and the nonlinearities arising from fabrication, i.e. initial stresses, geometric imperfections, and fastener details. In a quasistatic elizstic analysis the stresses from these sources are typically superimposed on the results of the elastic impact analysis. If any nonlinear behavior is considered in a transient dynamic analysis, it is no longer appropriate to superimpose stresses as they may influence the load history.

There are also several modelling issues that have not been resolved and require further study. During some impact scenarios stress waves in the shell walls may result in localized instabilities in the shells. These events occur over a few microseconds and, to some degree, will depend on the finite element model, i.e. finite element size, solution time step and material model. The extent to which the results presented here are influenced by modelling issues has not yet been investigated. Yet even with these modelling issues unresolved, the results of the transient dynamic inelastic analyses done here demonstrate that the behavior of the package is captured much more accurately compared to the results of elastic analyses. 


\section{Conclusions}

This report detailed the elastic and inelastic analyses of RAM rail and truck containers subjected to impacts onto a rigid target following a thirty-foot free fall in end-on, side-on, and center-of-gravity-over-corner orientations. Based on the comparison of results of these analyses, an improved knowledge of the behavior of the casks is obtained by using the transient dynamic inelastic analysis. The inelastic analysis predicts the yielding and load redistibution capability that the cask structural material has. This predictive capability leads to a better assessment of the structural safety of the design.

The design criteria currently used in the design of RAM transportation containers are taken from the ASME Boiler and Pressure Vessel Code. These load based criteria are ideally suited for pressure vessels where the loading is quasistatic and all stresses are in equilibrium with externally applied loads. For impact events, the use of load based criteria is less supportable. Impact events tend to be energy controlled, and thus, energy based criteria would appear to be more appropriate. Determination of an ideal design criterion depends on what behavior is desired. If the intent is that there will be no yielding in the package, an elastic analysis with an allowable stress less than the yield point stress is sufficient. This type of acceptance criterion will lead designers to using materials with the highest possible yield stress, and the associated lower ductility would perhaps lead to a lower margin of safety against gross rupture. However, if the goal is to prevent release of radioactive material, some amount of inelastic deformation is acceptable and perhaps desirable. In this case, the acceptance criterion should limit throughwall tearing and keep deformations to an acceptably small amount. An elastic analysis cannot predict the margin of safety against through-wall tearing or the deformations associated with an impact event nearly as well as an inelastic analysis. The overwhelming advantage of nonlinear dynamic analysis techniques is a better understanding of the response of the structure to the imposed environment. A better understanding of package behavior during impact events should lead to a safer package. 


\section{References}

[1] U.S. Nuclear Regulatory Commission Regulatory Guide 7.6, Design Criteria for the Structural Analysis of Shipping Cask Containment Vessels, Rev sion 1, March 1978

[2] Neilsen, M.K., H.S. Morgan, and R.D. Krieg, A Phenomenological Material Model for Low Density Polyurethane Foams, SAND86-2927, Sandia National Laboratories, Albuquerque, NM, 1986

[3] ASME Boiler and Pressure Vessel Code, Section III, Division I - Appendix F, 1983

[4] Case of ASME Boiler and Pressure Vessel Code, Case N-284 Metal Containment Shell Buckling Design Methods, Section III, Division I, Class MC, August 1980

[5] Dieter, G.E., Mechanical Metallurgy, Second Edition, McGraw-Hill, Inc. 1976

[6] Taylor, L.M. and Flanagan, D.P., PRONTO2D: A Two-Dimensional Transient Solid Dynamics Program, SAND86-0594, Sandia National Laboratories, Albuquerque, NM, 1987

[7] Taylor, L.M. and Flanagan, D.P., PRONTO3D: A Two-Dimensional Transient Solid Dynamics Program, SAND89-1912, Sandia National Laboratories, Albuquerque, NM, 1989. 


\section{Distribution}

U. S. Department of Energy (205)

Office of Scientific and Technical Information

Attn: DOE/OSTI-4500-R74 UC-722

Oak Ridge, TN 37830

U. S. Department of Energy (1)

Office of Technology Development

Clyde Frank, EM-50

7A-049

1000 Independence SW

Washington, DC 20585

U. S. Department of Energy (4)

Attn: R. Brancato, EM-56 (1)

D. Lillian, EM-56 (1)

L. Blalock, EM-561 (1)

E. McNeil, EM-561 (1)

Mail Stop EM-561

Washington, DC 20545

U. S. Department of Energy (2)

Albuquerque Operations Office

Albuquerque Headquarters

Attn: K. G. Golliher (1)

P. O. Box 5400

D. Bandy (1)

Albuquerque, NM 87115

Oak Ridge National Laboratory (1)

Attn: R. Rawl

P. O. Box 2008

Oak Ridge, TN 3783 $\$ 370$

James Hummer (1)

Westinghouse/Hanford Company

P. O. Box 1970, Mail Stop G2-02

Richland, WA 99352

William Lake (1)

U. S. Department of Energy, RW-431

Forrestal Building

1000 Independence Avenue SW

Washington, DC 20585

U.S. Nuclear Regulatory Commission (4)

Office of Nuclear Material Safety and Safeguards
Attn: Mr. C. Haughney (1)

R. Chappell (1)

H. Lee (1)

M. Radoitz (1)

Washington, DC 20555

\section{Sandia internal:}

$\begin{array}{lll}\text { MS0441 } & 1425 & \text { J. H. Biffle } \\ \text { MS0441 } & 1425 & \text { S. W. Attaway } \\ \text { MS0439 } & 1434 & \text { D. R. Martinez } \\ \text { MS0841 } & 1500 & \text { D. J. McCloskey } \\ \text { MS0836 } & 1501 & \text { C. W. Peterson (route to: } \\ & & \text { 1512,1513,1551,1552) } \\ \text { MS0827 } & 1502 & \text { P. J. Hommert (route to: } \\ \text { MS0443 } & 1561 & \text { H. S. Morgan } \\ \text { MS0443 } & 1561 & \text { M. W. Heinstein (5) } \\ \text { MS0443 } & 1561 & \text { G. W. Wellman } \\ \text { MS0437 } & 1562 & \text { R. K. Thomas } \\ \text { MS0483 } & 5165 & \text { J. M. Freedman } \\ \text { MS0483 } & 5165 & \text { R. E. Glass } \\ \text { MS0483 } & 5165 & \text { A. R. York } \\ \text { MS0726 } & 6600 & \text { J. B. Woodard } \\ \text { MS0715 } & 6603 & \text { R. E. Luna } \\ \text { MS0715 } & 6603 & \text { TTC Library (25) } \\ \text { MS0717 } & 6642 & \text { G. F. Hohnstreiter } \\ \text { MS0717 } & 6642 & \text { D. J. Ammerman (10) } \\ \text { MS0717 } & 6642 & \text { J. G. Bobbe } \\ \text { MS0717 } & 6642 & \text { D. C. Harding } \\ \text { MS0717 } & 6642 & \text { J. S. Ludwigsen } \\ \text { MS90118 } & 8523-2 & \text { Central Technical Files }\end{array}$


| 1

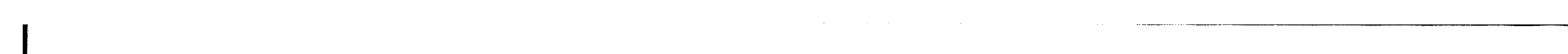

